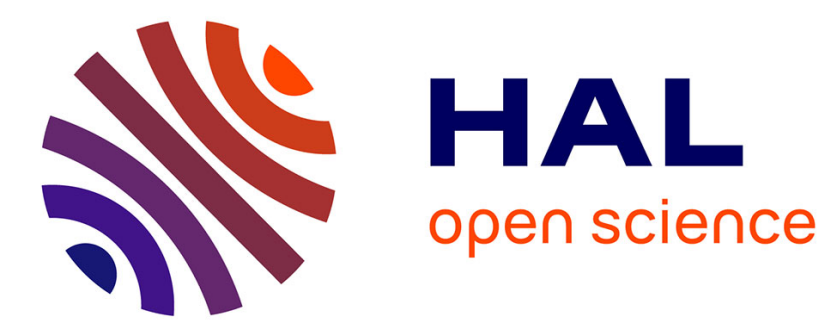

\title{
Capture-recapture models with heterogeneity to study survival senescence in the wild
}

Guillaume G. Péron, Pierre-André Crochet, Rémi Choquet, Roger Pradel, Jean-Dominique Lebreton, Olivier Gimenez

\section{- To cite this version:}

Guillaume G. Péron, Pierre-André Crochet, Rémi Choquet, Roger Pradel, Jean-Dominique Lebreton, et al.. Capture-recapture models with heterogeneity to study survival senescence in the wild. Oikos, 2010. hal-03502442

HAL Id: hal-03502442

https://hal.science/hal-03502442

Submitted on 25 Dec 2021

HAL is a multi-disciplinary open access archive for the deposit and dissemination of scientific research documents, whether they are published or not. The documents may come from teaching and research institutions in France or abroad, or from public or private research centers.
L'archive ouverte pluridisciplinaire HAL, est destinée au dépôt et à la diffusion de documents scientifiques de niveau recherche, publiés ou non, émanant des établissements d'enseignement et de recherche français ou étrangers, des laboratoires publics ou privés. 


\section{Capture-recapture models with heterogeneity to study survival senescence in the wild}

Authors:

Guillaume Péron ${ }^{(1)}$

Pierre-André Crochet ${ }^{(1)}$

Rémi Choquet $^{(1)}$

Roger Pradel ${ }^{(1)}$

Jean-Dominique Lebreton ${ }^{(1)}$

Olivier Gimenez ${ }^{(1)}$

Affiliation :

${ }^{\text {(1) }}$ Centre d'Ecologie Evolutive et Fonctionnelle UMR 5175

CNRS, 1919 Route de Mende 34293 Montpellier, Cedex 5 - France

Author for correspondence:

Guillaume Péron

Phone : +33(0)4 67613298

e-mail: guillaume.peron@cefe.cnrs.fr 


\section{Abstract}

Detecting senescence in wild populations and estimating its strength raises three challenges. First, in the presence of individual heterogeneity in survival probability, the proportion of high-survival individuals increases with age. This increase can mask a senescence-related decrease in survival probability when the probability is estimated at the population level. To accommodate individual heterogeneity we use a mixture model structure (discrete classes of individuals). Second, the study individuals can elude the observers in the field, and their detection rate can be heterogeneous. To account for detectability issues we use capture-markrecapture (CMR) methodology, mixture models and data that provide information on individuals' detectability. Last, emigration to non-monitored sites can bias survival estimates, because it can occur at the end of the individuals' histories and mimic earlier death. To model emigration we use Markovian transitions to and from an unobservable state. These different model structures are merged together using hidden Markov chain CMR models, or multievent models. Simulation studies illustrate that reliable evidence for survival senescence can be obtained using highly heterogeneous data from non site-faithful individuals. We then design a tailored application for a dataset from a colony of black-headed gull Chroicocephalus ridibundus. Survival probabilities do not appear individually variable, but evidence for survival senescence becomes significant only when accounting for other sources of heterogeneity. This result suggests that not accounting for heterogeneity leads to flawed inference and/or that emigration heterogeneity mimics survival heterogeneity and bias senescence estimates.

\section{Additional Key-Words}

Ageing, Capture-recapture, Dispersal, E-SURGE, Larus. 


\section{Introduction}

2 Senescence, the decline in fitness components with age due to internal physiological

3 deterioration (Medawar 1952), has been evidenced in several life-history traits in a variety of

4 wild vertebrates (e.g. Loison et al. 1999; Crespin et al. 2006; Nussey et al. 2006) and is

5 thought to be the rule for most (or all) vertebrate species (see Finch 1990; Jones et al. 2008).

6 Yet, several demographic studies of wild populations found no decline in individuals'

7 performance with age (Nichols et al. 1997; Miller 2001; Pistorius and Bester 2002; Congdon

8 et al. 2003), fuelling a debate over the validity of their results.

Among the potential flaws of demographic studies of senescence, the non-modelled

10 effect of individual heterogeneity is recurrent (Vaupel and Yashin 1985; Cam et al. 2002;

11 Zens and Peart 2003; van de Pol and Verhulst 2006). Individual heterogeneity can be defined

12 as the occurrence of systematic variation among individuals in demographic parameters. It

13 can originate from genetic differences or differences in the conditions experienced during

14 development (Fox et al. 2006), variation in individual strategies or quality (e.g. covariation

15 between reproductive effort and survival: Hamel et al. 2008), sex-bias in dispersal or

16 behaviour or the interplay of behavioural differences and study design (e.g. social status- or

17 body condition-dependent detectability: Whitehead and Wimmer 2005; Regehr et al. 2007;

Crespin et al. 2008). Individual heterogeneity can lead to population-level patterns that are not always representative of the actual relationship at the individual level (Vaupel and Yashin 1985). In the case of senescence studies, since the proportion of individuals with high survival

21 probability will tend to increase with age, the age-specific population average of survival probability, which is used in most studies of survival senescence, might not decrease or might even increase with age (Vaupel and Yashin 1985; Fig. 1). 
modelled an effect of the year of birth and family structure. Yet, the precise cause of heterogeneity is often not identified, or not measured. Two ways to accommodate individual variation of unknown origin have been proposed: continuous random effects (e.g. Cam et al. 2002; Royle 2008) and mixture models that consider discrete classes of heterogeneity (Pledger et al. 2003; Pradel 2009).

In addition, it is well known that analysing data on marked individuals with models that do not formally estimate detection probabilities together with other demographic parameters (Lebreton et al. 1992) can bias estimations of demographic parameters, including the rate of senescence (Gimenez et al. 2008). Individual heterogeneity in detection rate also biases survival estimates downwards if not accounted for (Pradel et al. 1997; Prévot-Julliard et al. 1998a) and it violates the fundamental assumption of parameter homogeneity in CMR models (Lebreton et al. 1992), which can lead to flawed inference (Burnham and Anderson 2002). Last, temporary emigration to non-monitored sites, such that individuals missing during several capture occasions might still be alive elsewhere (Burnham 1993; Fujiwara and Caswell 2002), evidently impacts on the estimation of "true" (as opposed to "local") survival probability. If emigration probability is subject to individual heterogeneity, patterns similar to heterogeneity in survival might appear in the data. Consequently, heterogeneity in temporary emigration can affect the detection of survival senescence as well. In short, we identified three features of population studies (individual heterogeneity, imperfect detectability, temporary emigration out of the study area) which, when not included in the population models, can bias estimates of senescence and/or cause a lack of fit that leads to flawed inference.

Multievent models have been introduced as a unified framework by Pradel (2005). They extend multistate models, in which individuals move between states or die and can at each occasion be detected or not, by considering that the state of an individual is imperfectly determined when it is observed. Their structure rests on the more general framework of 
hidden Markov chain models (McDonald and Zucchini 1997). The introduction of this model structure in the field of CMR data analysis was initially motivated by capture heterogeneity as reviewed by Pledger (2000). The use of hidden Markov chains in cases not related to individual heterogeneity was to our knowledge initiated by Nichols et al. (2004). These authors modelled a situation where males and females had different survival probabilities, but could not always be separated in the field because of reduced sexual dimorphism. Since then, following the development of the software E-SURGE (Choquet et al. 2009a) numerous applications have been proposed (see Pradel 2009). Among others, the implementation of memory models (where demographic parameters depend on the states occupied during the two preceding time steps) is made more straightforward through the use of hidden states (Rouan et al. 2009), and epidemiology models can be fitted to data where health status determination is uncertain or incomplete (Conn and Cooch 2009).

In this paper we show how this recently developed modelling framework can be used to overcome the types of heterogeneity that typically plague senescence studies. Although these developments are quite general and can be applied to other study situations and taxa, we specifically tailor our example to a study of black-headed gulls Chroicocephalus ridibundus. This is a species for which survival senescence is likely to occur (Pugesek et al. 1995; Cam et al. 2002 in related species), but a population in which strong heterogeneities are expected (see "Study site and population" in the method section). After presenting the dataset and the features that suggested the need for this new development in CMR models, we present this development and provide simulations that illustrate their performance. 


\section{Methods}

73

\section{Study site and population}

Black-headed Gull (Chroicocephalus ridibundus) are long-lived Charadriiform birds

(maximum longevity recorded in our study area: 30 years) and breed colonially, often on vegetated ponds. The data come from a long-term monitoring program of Black-headed Gulls breeding in La Ronze (noted LR) pond, a large (more than 4000 pairs in recent years) colony located in the Forez basin, at Craintilleux, central France $\left(45^{\circ} 35^{\prime} \mathrm{N} 4^{\circ} 14^{\prime} \mathrm{E}\right)$. In this population, detection is known to vary between individuals because nests are built within vegetation or at its edge and because a large proportion of the re-sightings are made on the nests (PrévotJulliard et al. 1998a). Note that some re-sightings are made on other perches so that all birds are potentially detectable even if their nests are not visible. Additionally, preliminary results in the same population indicated that dispersal rates were individually variable, in particular because of differences between males and females (Grosbois 2001), as is commonplace in birds (Greenwood 1980). Yet, for both detection and emigration, we only had very partial information on the characteristics of the birds in the field. Detectability cannot be assessed for nests which are not visible of course and can't be evaluated for birds seen on other perches. Furthermore, Black-headed Gulls are only weakly sexually dimorphic, which precludes sexing of most birds in the field. It was thus clear that accounting for unknown or unmeasured sources of variation between individuals would be very useful if we were to assess survival senescence in this population.

Previous work in the same population indicated that time effects on survival probabilities were reduced or absent (Prévot-Julliard et al. 1998a; Grosbois 2001). We were thus confident that, despite most observations of old individuals occurred at the end of the time series, unaccounted time effects could not confound age effects. 


\section{Data collection}

Chicks were ringed before fledging with stainless steel rings. The use of stainless rings is particularly appropriate for the study of senescence since they almost do not wear with age (in all occasions when a known-age adult was physically recaptured at age $>14$, the code was perfectly readable and the ring could not be removed even with the use of pliers).

Observations of ringed adults were conducted using a floating blind from which metal ring codes could be read with a telescope (Lebreton, 1987). At each observation of a ringed adult, we recorded whether it attended a nest or was feeding chicks, which would confirm its status as breeder. Now, an individual nesting in an accessible location had a high probability to be confirmed as breeder, whereas an individual breeding in a less accessible part of the colony was more often observed on roosts or other perches and was more likely to end up with an unconfirmed breeding status. The confirmation of breeding status thus potentially yielded information on the detection probability.

We analyzed the survival of 1556 stainless-ringed adults, for a period of 28 years (from 1978 to 2006), starting from their first re-observation in LR, which occurred from age two to age 23 (mean 5.5; SD 4.1). The large range of age at first resighting is partly due to the fact that black-headed gulls are not present on the colony before starting to reproduce between two and six year-old (Clobert et al. 1994), partly due to the non-exhaustiveness of detection and partly due to the fact that some birds start breeding on other colonies and disperse toward LR after several breeding attempts (Péron et al. submitted). The data were coded with one digit per year: '0' (not observed), '1' (confirmed breeder) or '2' (non-confirmed breeder) 


\section{Model description}

\section{1) Multievent models for the study of black-headed gull senescence}

119 As introduced above, our approach was based upon multievent CMR models (Pradel 2005).

120 The observer records "events" (here "not seen", "confirmed breeder", "non-confirmed

121 breeder") that carry uncertain information on the state that the individual occupies at the

122 current sampling occasion (see below and Appendix S1 for state description). The

123 relationship between states and events is thus probabilistic (Pradel 2005).

All models were fully described by first considering the vector of probabilities of initial presence in the various states (П-vector), then linking states at successive sampling occasions by the matrix of survival/transition probabilities ( $\Phi$-matrix), exactly like in multistate models, while the events were linked to states by the matrix of event probabilities (B-matrix). For convenience we separated $\Phi$ in two steps (S-matrix for survival probabilities and $\Psi$-matrix for dispersal probabilities), and B (P-matrix for detection probabilities and Rmatrix for probabilities to confirm breeding status when detected). Full details on the model

131 structure and examples of these matrices are presented in Appendix S1.

\section{2) Individual heterogeneity}

133 Discrete classes of individuals were built to accommodate heterogeneity, each class being

134 associated with a distinct value of the parameter(s) (Pradel 2009); these classes were the

135 actual states of the multievent model. For a simple example, in a model with a two-class

136 heterogeneity structure for survival probability and no possibility to emigrate [model $\left\{\varphi\left(\mathrm{h}_{2}\right)\right.$,

$137 p()$.$\} of Pledger et al. (2003)], there will be a state "low survival" and a state "high survival".$

138 In this model, the probability of the five first events in the first example history is:

$$
\begin{aligned}
& P(11010= \\
& \pi_{1}^{H} s_{1}^{H} p_{2} s_{2}^{H}\left(1-p_{3}\right) s_{3}^{H} p_{4}\left[s_{4}^{H}\left(1-p_{5}\right)+\left(1-s_{4}^{H}\right)\right] \\
& +\left(1-\pi_{1}^{H}\right) s_{1}^{L} p_{2} s_{2}^{L}\left(1-p_{3}\right) s_{3}^{L} p_{4}\left[s_{4}^{L}\left(1-p_{5}\right)+\left(1-s_{4}^{L}\right)\right]
\end{aligned}
$$


Superscripts $\mathrm{H}$ and $\mathrm{L}$ refer to high and low survival classes respectively; subscripts refer

141 to time-dependence. $\pi, s, p$ stand respectively for the probabilities of initial state, survival, and

142 detection. The situation is similar to having two possible paths at first observation: one low-

143 survival and one high-survival path (Fig. 2). The "low survival" path has the greatest

144 probability in "short" histories like '1101000000000' and the lowest in "long" histories like

145 '1000001000001' (Fig. 2).

146 In a more complex model, there are a larger number of possibilities when individuals

147 are not encountered. In the presence of several kinds of heterogeneity (survival, emigration,

148 and detection), an individual can be in the low or the high-value class for each type of

149 heterogeneity. There is up to 8 "classes of heterogeneity" (see Appendix S1 part 4) in the

150 models, which greatly complicates the computation of history probabilities. The need for an

151 algorithm to calculate history probabilities should therefore be apparent. We used program E-

152 SURGE 1.1.1 (Choquet et al. 2009a) to obtain maximum likelihood estimates of the

153 parameters and perform model selection. A more rigorous and general development of the

154 likelihood using matrix notation is presented in Appendix S1.

155 In the following, survival is time-independent and detection is time-dependent, based on

156 results of Prévot-Julliard et al. (1998a) and Grosbois (2001).

\section{3) Temporary emigration}

158 We modelled temporary emigration as Markovian or state-dependent transitions to and from a

159 site where detection probability is zero (Fujiwara and Caswell 2002; Schaub et al. 2004; Fig

160 2; Appendix S1 part 2). Colonies that were not searched for marked individuals were grouped

161 in a single non-observable "site" denoted "alive elsewhere" (AE hereafter). This site was

162 included in the usual multisite CMR models formulation (Arnason, 1972, 1973; Schwarz et al.

163 1993) with the only difference that the detection rate was zero. Once in the state AE,

164 individuals lost their classification as low/high detection and low/high emigration. Therefore, 
upon returning to the study site, they could become more/less detectable, or more/less site-

166 faithful, than what they were before emigrating (see Appendix S1 part 2 for justification).

4) Modelling age-effects on survival when individuals enter the dataset at various ages

The straightforward implementation of age effects in the sense of CMR models (Lebreton et al. 1992) corresponds to the effect of time elapsed since first occurrence in the dataset (hereafter TFC to match a previous acronym: Crespin et al. 2006). In our case gulls were marked as chicks and were thus of known age, but they entered the dataset as adults in the colony at a varying age (Clobert et al. 1994). TFC did thereby not correspond to true age. To model the effect of true age, we had to constrain survival to vary with time across as many groups as there were ages at first occurrence in the dataset (hereafter "group approach"; described in details in Appendix S1 part 2). This procedure was computer-time-hungry [around 24h were needed to fit such a model using an Intel Pentium 4HT, 2.6GHz (3.25 x 800) processor with $512 \mathrm{Mb}$ of system memory, vs. less than $1 \mathrm{~h}$ for a TFC model] and was thus impractical for model selection which required running many models sequentially. Yet using TFC as a proxy for true age in a similar study design does not prevent the detection of survival senescence as shown by Crespin et al. (2006). A test of power (Crespin et al. 2006) indicated that sample size rather than the use of TFC vs. true age is the most critical factor preventing the detection of senescence. The main drawback of using TFC is that individuals of various true ages are mixed in a same TFC-class, thus creating noise and

184 increasing the standard error on the estimation of the strength of senescence. Model selection

185 using TFC was therefore considered conservative for what concerns the detection of senescence. We thus used TFC instead of age to select for the best model, and then confirmed our results by running the preferred model with true age instead of TFC. used a constrained piecewise relationship; we modelled a separate survival probability at age 
190 1, a plateau lasting until 14-years old and a log-linear decrease in survival with age afterwards

191 (see Appendix S1 part 2 for justification).

5) Modelling observations that provide information on detectability

193 As described in the "data collection" section, the confirmation of breeding status conveyed

194 information on the detectability of individuals. Models accommodating such data structure

195 were introduced by Nichols et al. (2004; the individual status was the gender, documented by

196 behaviour) and Conn and Cooch (2009; the individual status was the state of health,

197 documented by visible symptoms). In the present paper, the class of detection heterogeneity

198 was documented by the breeding status (Appendix S1 for practical implementation).

\section{Model selection}

200 There were 16 models in our candidate set representing every combination of 201 presence/absence of the four considered effects: age-effect on survival, heterogeneity in 202 survival, detection and emigration probabilities. The most general model we considered 203 included heterogeneity in survival, emigration and detection probabilities as well as age-effect 204 and had 11 states (model denoted $\left\{\mathrm{S}_{\mathrm{H}+\mathrm{a}} ; \mathrm{D}_{\mathrm{H}} ; \mathrm{E}_{\mathrm{H}}\right\}$; Appendix $\mathrm{S} 1$ part 4). Subscripts $H$ and $O$ 205 referred to models with and without heterogeneity in survival (denoted $S$ ), detection (denoted $206 D$ ) and emigration (denoted $E$ ) probabilities, while subscripts $+a$ and $+\bar{a}$ referred to models 207 with and without age-effect on survival. The lowest AIC-model (with a two AIC-points 208 difference) was preferred (Akaike's Information Criterion; Burnham and Anderson 2002). 209 However, all models in which a given effect was included could be considered as 210 "redundant". Therefore, the importance value of each effect was computed as the sum of the 211 AIC-weights of the models including the considered effect, and it was interpreted as the 212 probability that the effect was present in the data (Burnham and Anderson 2002). 


\section{Goodness-of-fit}

214 Goodness-of-fit (GOF) tests were performed on raw capture/non capture histories (formed of

215 ' 0 ' and ' 1 ' thus discarding the details about age at first detection and breeding status; note that

216 all the data concerned a single site). One of the main consequences of heterogeneity in

217 detection probability is an excess (when compared to homogeneous datasets) of encounter

218 histories with consecutive "captures" (i.e. runs of '1') and consecutive "non-captures" (i.e.

219 runs of '0'). Such histories indicate the presence of highly and poorly detectable individuals,

220 respectively. Some of the runs of ' 0 ' will occur at the end of the capture history. As a

221 consequence detection heterogeneity tends to induce both "transience" (i.e. lower chance of

222 recapture of first-encountered individuals than already encountered ones; Pradel et al. 1997)

223 and "trap-happiness" (i.e. higher probability to encounter at time $\mathrm{t}+1$ the individuals

224 encountered at time $t$ than the individuals not encountered at time $t$ but known to be alive

225 because of previous and future recaptures; Pradel 1993).

226 One-sided directional test statistics are the signed square roots of the chi-squared

227 statistics for the corresponding tests: Test3.SR for transience and Test2.CT for trap-

228 dependence (Pradel 1993; Pradel et al. 1997; Pradel et al. 2005; practical implementation

229 detail in Choquet et al. 2005). They are the most relevant statistics for the detection of

230 transience and trap-happiness respectively (Pradel et al. 2005) and are inflated by individual

231 heterogeneity.

232 We used techniques for partitioning chi-squares variables (Rao, 1973 pp. 185 and

233 following) to approximate a GOF test for a time-dependent model with capture heterogeneity

234 as follow: $(i)$ we computed the overall GOF chi-squared statistics for transience and trap-

235 dependence, from Test3 and Test2 respectively (Pradel 1993; Pradel et al. 1997; Choquet et

236 al. 2005) (ii) we computed the directional statistics, from Test3.SR and Test2.CT respectively

237 (iii) we removed from the overall statistics the corresponding squared directional statistics 
238 (which are asymptotically distributed as $\chi^{2}{ }_{1}$ ), and we obtained non-directional components

239 with one degree of freedom less. These components corresponded to a GOF test for a model

240 where sources of transience and trap-happiness (here, individual heterogeneity) were

241 accounted for. If this corrected test still proved statistically significant, we used an

242 overdispersion coefficient $\hat{c}$, computed as the ratio between the chi-squared statistic and the

243 degree of freedom, in the model selection procedure (Burnham and Anderson 2002). All the

244 GOF test components were computed using U-CARE (Choquet et al. 2009b)

\section{Simulation study}

246 To judge whether the results provided by the proposed methodology were reliable in a

247 complex but known case (three kinds of heterogeneity and a decrease in survival probability

248 with age), we carried out Monte Carlo simulation studies (Appendix S2). Very briefly, these

249 exercises illustrated that the multievent framework allowed (i) detecting simultaneously and

250 using AIC all three kinds of heterogeneities when present, and (ii) obtaining reliable evidence

251 and precise estimates for survival senescence by accounting for these heterogeneities.

252 More precisely the simulation study indicated (i) that the magnitude of the age-effect on

253 survival was very precisely retrieved when the heterogeneity structure in the model exactly

254 matched the simulated structure, and (ii) that bringing additional information on detectability

255 of individuals was sufficient (and necessary) to separate detectability and emigration

256 heterogeneities. In our case, such information was provided by the confirmation of breeding

257 status. The main drawbacks of the method were the non-reliability of emigration probability

258 estimates (the presence of emigration heterogeneity was retrieved, but the actual values of the

259 parameters were not), and the fact that, most probably because the data on them were sparse,

260 estimates for parameters associated to low-survival individuals were often inaccurate. 


\section{Results}

\section{Black-headed gull dataset: Goodness-of-fit}

263

As expected, the directional tests for transience and trap-happiness were statistically significant, which is a cue for heterogeneity in detection (Table 1). The corrected Test3.SR and Test2.CT were statistically non significant, and the overall corrected GOF test indicated that there was no need to account for any overdispersion (Table 1). This test indicated that a time-dependent model with heterogeneity in detection probability fitted the data. Thus, accounting for other sources of heterogeneity could only improve the fit.

\section{Modelling age-dependence and testing for senescence}

\section{1) Model selection using TFC}

There was strong support for a model with individual heterogeneity in both detection and emigration probabilities, along with TFC-effect on survival (Table 2: model $\left.\left\{\mathrm{S}_{0+a} ; \mathrm{D}_{\mathrm{H}} ; \mathrm{E}_{\mathrm{H}}\right\}\right)$. This model was nearly four AIC-points lower and three times more likely than the next model (as indicated by the ratio of AIC-weights). The importance value (computed as the sum of the AIC-weights of the models in which the considered effects occurred) of the TFC-effect on survival probability was 0.83 , which we interpret as a high probability for a decrease in survival with age. These results supported the existence of survival senescence in the population, although the slope of the TFC-effect was statistically not different from zero: 0.16 (95\% CI: -0.49; 0.17); see next section.

Importance values of heterogeneity in survival, detection and emigration were 0.09 , 0.94, and 0.78 , respectively. We interpret these values as high probability that two-class heterogeneity structure was present in detection and emigration probabilities, and low probability that such heterogeneity was present in survival probability. As discussed later, we 
284

do not exclude that the discrete-class heterogeneity models were unable to detect small, continuous individual variation in survival probability.

The second best model (Table 2: model $\left\{\mathrm{S}_{0+\overline{\mathrm{a}}} ; \mathrm{D}_{\mathrm{H}} ; \mathrm{E}_{0}\right\}$ ), as opposed to the best model, did not account for heterogeneity in emigration probability and, most importantly, did not include any variation in survival probability with TFC. This result means that, when not accounting for heterogeneity in emigration probabilities, the selection procedure discarded TFC-effect on survival, in other words the detection of survival senescence was prevented.

\section{2) Parameter estimates in the true age formulation}

Parameter estimates are from the preferred model $\left\{\mathrm{S}_{0+\mathrm{a}} ; \mathrm{D}_{\mathrm{H}} ; \mathrm{E}_{\mathrm{H}}\right\}$, ran using true age instead of TFC. Prime age survival (between 2 and 14 years old) was 0.84 (95\% CI: 0.79; 0.88) and the slope of the decrease in survival after age 14 was $-0.16(-0.30 ;-0.02)$ on a logit scale (Fig. 3). Thus, when comparing true age- (this model) and TFC-models (previous section), we observed that the use of TFC increased the error on the estimated slope of the decrease in survival with age, as expected, but did not modify the value of the estimate.

The estimated temporary emigration probabilities to state AE were $0.17(0.03 ; 0.54)$ in stayers and $0.67(0.28 ; 0.91)$ in movers. The estimated detection probabilities (averaged over time) were $0.08(0.05 ; 0.10)$ and $0.48(0.41 ; 0.55)$ in the low- and high-detectability classes. The estimated proportion of sightings on the nest or with chicks was $0.53(0.44 ; 0.63)$ for the low-detectability class and $0.61(0.56 ; 0.66)$ for the high-detectability class.

\section{Discussion}

\section{Detecting senescence in wild populations}

We used multievent framework to combine three pre-existing types of CMR models that were potentially required to fit the gull data: heterogeneity models with discrete classes (Pledger et al. 2003; Pradel 2009), temporary emigration models (Fujiwara and Caswell 2002; Schaub et 
al. 2004), and models accommodating partial information on individual status (Nichols et al. 2004; Conn and Cooch 2009). The framework was flexible enough to combine these model structures which had only been used separately until now.

312 heterogeneity in temporary emigration in the models (Table 2), which illustrates the interest 313 of complex models mixing several possible causes of heterogeneity. This result was perhaps

314 not unexpected since temporary emigration events occurring at the end of an individual's life,

315 when not followed by a detection event, could mimic earlier death. Thereby, emigration

316 heterogeneity might have created patterns in the data similar to heterogeneity in survival, and

317 prevented the detection of survival senescence when not accounted for. However, our

318 simulation studies only weakly supported this purported effect of non modelled heterogeneity

319 in temporary emigration on the detection of survival senescence. The result that senescence

320 was discarded when not accounting for emigration heterogeneity might therefore originate

321 from a lack-of-fit impairing the model selection when models did not include the appropriate 322 heterogeneity structure.

323 Definitive emigration has evidently an even greater impact on survival estimates than 324 temporary emigration, but it can only be modelled if recoveries data (i.e. rings recovered on 325 birds shot or found dead throughout the year) are available (Burnham 1993).

326 In senescence studies, we thus recommend that (i) emigration is modelled when field 327 observations indicate its presence and (ii) either individual heterogeneity is explicitly 328 considered or evidence for its absence is provided by GOF tests or biological considerations. 329 In particular, empirical support for the absence of senescence in animals (e.g. Nichols et al. 330 1997; Miller 2001; Pistorius and Bester 2002; Congdon et al. 2003) should be considered with 331 caution until the results are verified with analyses accounting for heterogeneity. 
332

\section{Sources of heterogeneity in the gull dataset: emigration, detectability}

Although there was a strong support for the existence of low- and high- emigration classes in our population, biological explanations are not straightforward. Emigration heterogeneity might also include the skipping of breeding attempts and the effect of early nest failures.

These two phenomena result in an absence of the individuals from the colonies during fieldwork (thereby mimicking temporary emigration), and they are influenced by individual quality (Calladine and Harris 1997), a well known source of heterogeneity in demographic parameters (Hamel et al. 2008 and references therein). Moreover, true temporary emigration, reproduction failures and reproduction skipping do not occur at the same frequency which might create individual heterogeneity when they are modelled using a same transition probability. Alternatively, individual heterogeneity in true temporary emigration rate could stem from sex-biased dispersal (Greenwood, 1980) or from heterogeneity in individual quality and/or the conditions experienced during early life or previous reproduction attempts, both of which are known to affect habitat choice and dispersal behaviours (Switzer 1997; Clobert et al. 2009). Last, and perhaps more speculatively, heterogeneity in dispersal behaviour can result from genetically determined differences in "personalities" or other behavioural syndromes (see e.g. Cote \& Clobert, 2007; Clobert et al. 2009). Tradeoffs between investment in exploration-dispersal and in other traits (Wolf et al. 2007) or frequency-dependent selection acting through environmental stochasticity (see Dingemanse et al. 2004) can maintain stable polymorphism in dispersal tendencies.

Heterogeneity in detection probability was probably related to the fact that high vegetation density hindered the detection of birds breeding far inside the vegetation. These are likely to have strongly contributed to the class with a low detection probability and a low proportion of sightings on a nest. Such heterogeneity in detection induced by habitat 
Péron et al.

heterogeneity in the study site is supposedly common, and we recommend it be explicitly incorporated.

\section{Individual heterogeneity of unknown origin: modelling approach}

359 As in most modelling exercises, our study relied on some untested assumptions. Modelling

360 individual heterogeneity using discrete classes was a priori appropriate in our study: birds

361 could breed inside vegetation vs. outside vegetation, their movements could occur within vs.

362 outside of the colony. However, we do not claim that the discrete-class model represented

363 individual variation in survival probabilities better than a continuous individual random effect

364 could (e.g. Royle 2008, but see Pledger 2005). Concerning the number of heterogeneity

365 classes, Pledger (2005) indicated that, as a theoretic and approximated representation of

366 individual heterogeneity, the two-class models were more parsimonious than models with

367 more classes, excepted in the presence of strong multimodality in the true distribution of the

368 parameters of interest. Standard quantitative tools such as AIC generally fail to separate

369 different forms of heterogeneity models (own results not shown; Pledger 2005). We suggest

370 that information on the study system from the field might be the most reliable cue when

371 deciding which form of individual heterogeneity to incorporate in CMR models.

\section{Performance and identifiability issues}

373 The simulation studies illustrated that reliable evidence for survival senescence could be

374 obtained in the simultaneous presence of three kinds of heterogeneity. When the data included

375 events whose frequency depended on detectability, the three sources of heterogeneity were

376 separately identifiable, although in most cases only the structure and not the actual values of

377 emigration probabilities were retrieved. The magnitude of the age-effect was very precisely

378 retrieved when the heterogeneity structure in the model exactly matched the way data was

379 simulated. In the gull application we did not detect any parameter redundancy issue using the 
380

381

382

383

384

385

386

387

rank of the models' numeric derivative matrix (Rouan et al. 2009 Appendix A; Choquet et al. 2009a pp. 56-57). Overall our results are therefore encouraging for the application of multievent models to the study of population dynamics of species with complex life-histories, weak or variable site-fidelity, or inhabiting very heterogeneous habitats.

\section{References}

Arnason, A.N. 1972. Parameter estimates from mark-recapture experiments on two populations subject to migration and death. - Res. Popul. Ecol. 13: 97-113.

Arnason, A.N. 1973. The estimation of population size, migration rates and survival in a stratified population. - Res. Popul. Ecol. 15: 1-8.

Burnham, K. P. 1993. A theory for combined analysis of ring recovery and recapture data. In: Lebreton, J. D. and North, P. H. (eds.), Marked individuals in the study of bird population. Birkhäuser Verlag, Basel, Switzerland.

Burnham, K.P. and Anderson, D.R. 2002. Model selection and multimodel inference: a practical information-theoretic approach, 2nd edition - Springer-Verlag, New York.

Calladine, J. and Harris, M.P. 1997. Intermittent breeding in the Herring gull Larus argentatus and the Lesser black-backed gull Larus fuscus. - Ibis 139: 259-63.

Cam, E. et al. 2002. Individual covariation in life-history traits: seeing the trees despite the forest. - Am. Nat. 159: 96-105.

Choquet, R. 2008. Automatic generation of multistate capture-recapture models. - Can. J. Stat. 36: 43-57.

Choquet, R. et al. 2005. U-CARE 2.2 User's Manual - CEFE, Montpellier, France.

Choquet, R. et al. 2009a. Program E-SURGE: a software application for fitting Multievent models. - In: Thomson, D. L. Cooch, E. G. and Conroy, M. J. (eds.), Modelling Demographic Processes in Marked Populations, pp. 845-865. 
Péron et al.

405 Choquet, R. et al. 2009b. U-CARE: Utilities for performing goodness of fit tests and 406 manipulating CApture-REcapture data. Ecography. In press.

407 Clobert, J. et al. 1994. The estimation of age-specific breeding probabilities from recaptures 408 or resightings in vertebrate populations.2. Longitudinal models. - Biometrics 50: 375-87. 409 Clobert, J. et al. 2009. Informed dispersal, heterogeneity in animal dispersal syndromes and 410 the dynamics of spatially structured populations. - Ecol. Lett. 12: 197-209.

411 Congdon, J.D. et al. 2003. Testing hypotheses of aging in long-lived painted turtles 412 (Chrysemys picta). - Exp. Gerontol. 38: 765-72.

413 Conn, P.B. and Cooch, E.G. 2009. Multistate capture-recapture under imperfect state 414 observation: an application to disease models. - J. Appl. Ecol. 46: 486-492.

415 Cote, J. and Clobert, J. 2007. Social personalities influence natal dispersal in a lizard. - P. 416 Roy. Soc. Lond. B Bio. 274: 383-390.

417 Crespin, L. et al. 2008. Is heterogeneity of catchability in capture-recapture studies a mere 418 sampling artefact or a biologically relevant feature of the population? - Popul. Ecol. 50: $419 \quad 247-256$.

420 Crespin, L. et al. 2006. Increased adult mortality and reduced breeding success with age in a 421 population of Common guillemot Uria aalge using marked birds of unknown age. - J. $422 \quad$ Avian Biol. 37: 273-282.

423 Dingemanse, N. J. Both, C. Drent, P. J. et al. 2004. Fitness consequences of avian 424 personalities in a fluctuating environment. - P. Roy. Soc. Lond. B Bio. 271: 847-852. 425 Finch, C. E. 1990. Longevity, senescence, and the genome. - University of Chicago Press, 426 Chicago, USA.

427 Fox, G.A. et al. 2006. Consequences of heterogeneity in survival probability in a population 428 of Florida scrub-jays. - J. Anim. Ecol. 75: 921-927. 
Péron et al.

429

430

431

432

433

434

435

436

437

438

439

440

441

442

443

444

445

446

447

448

449

450

451

452

Fujiwara, M. and Caswell, H. 2002. A general approach to temporary emigration in markrecapture analysis. - Ecology 83: 3266-3275.

Gimenez, O. et al. 2008. The risk of flawed inference in evolutionary studies when detectability is less than one. - Am. Nat. 172: 441-448.

Greenwood, P.J. 1980. Mating systems, philopatry and dispersal in birds and mammals. Anim. Behav. 28: 1140-1162.

Grosbois, V. 2001. La dispersion : trait d'histoire de vie et paramètre démographique : étude empirique dans une population de mouette rieuse. $\mathrm{PhD}$ thesis - Univ. Montpellier II, Montpellier, France. In French.

Hamel, S. et al. 2008. Individual variation in reproductive costs of reproduction: high-quality females always do better. - J. Anim. Ecol. 78: 143-151.

Jones, O. R., Gaillard, J.-M., Tuljapurkar, S., et al. 2008. Senescence rates are determined by ranking on the fast-slow life-history continuum. - Ecol. Lett. 11: 664-673.

Lebreton, J.D. 1987. Régulation par le recrutement chez la Mouette rieuse Larus ridibundus. - Rev. Ecol.- Terre Vie Suppl. 4: 173-187. In French.

Lebreton, J.D. et al. 1992. Modelling survival and testing biological hypotheses using marked animals - a unified approach with case-studies. - Ecol. Monogr. 62: 67-118.

Loison, A. et al. 1999. Age-specific survival in five populations of ungulates: evidence of senescence. - Ecology 80: 2539-2554.

MacDonald, I. L. and Zucchini, W. 1997. Hidden Markov and other models for discretevalued time series. - Chapman and Hall, London.

Medawar, P.B. 1952. An unsolved problem of biology. - Lewis, London.

Miller, J.K. 2001. Escaping senescence: demographic data from the Three-toed box turtle (Terrapene carolina triunguis). - Exp. Gerontol. 36: 829-832. 
Péron et al.

453 Nichols, J.D. et al. 1997. Test for senescent decline in annual survival probabilities of

454 Common pochard, Aythia ferina. - Ecology 78: 1009-1018.

455 Nichols, J.D. et al. 2004. Estimation of sex-specific survival from capture-recapture data

456 when sex is not always known. - Ecology 85: 3192-3201.

457 Nussey, D.H. et al. 2006. The rate of senescence in maternal performance increases with

458 early-life fecundity in red deer. - Ecology Letters 9: 1342-1350.

459 Pistorius, P.A. and Bester, M.N. 2002. A longitudinal study of senescence in a pinniped. -

$460 \quad$ Can. J. Zool. 80: 395-401.

461 Pledger, S. 2000. Unified maximum likelihood estimates for closed capture-recapture models

462 using mixtures. - Biometrics 56: 434-442.

463 Pledger, S. 2005. The performance of mixture models in heterogeneous closed population

464 capture-recapture. - Biometrics 61: 868-873.

465 Pledger, S. et al. 2003. Open capture-recapture models with heterogeneity: I. Cormack-Jolly-

466 Seber model. - Biometrics 59: 786-794.

467 Pradel, R. 1993. Flexibility in survival analysis from recapture data: handling trap-

468 dependence. - In: Lebreton, J. D. and North, P. H. (eds.), Marked individuals in the study of 469 bird population, pp. 29-37.

470 Pradel, R. 2005. Multievent: an extension of multistate capture-recapture models to uncertain $471 \quad$ states. - Biometrics 61: 442-447.

472 Pradel, R. 2009. The stakes of capture-recapture models with state uncertainty. - In:

473 Thomson, D. L. Cooch, E. G. and Conroy, M. J. (eds.), Modeling Demographic Processes in $474 \quad$ Marked Populations, pp. 781-795.

475 Pradel, R. et al. 2005. Principles and interests of GOF tests for multistate capture-recapture 476 models. - Anim. Biodivers. and Conserv. 28: 189-204. 
Péron et al.

477 Pradel, R. et al. 1997. Capture-recapture survival models taking account of transients. -

478 Biometrics 53: 60-72.

479 Pradel, R. et al. 2007. Estimation of sex-specific survival with uncertainty in sex assessment.

$480 \quad-$ Can. J. Stat. 36: 29-42.

481 Prévot-Julliard, A.C. et al. 1998a. Re-evaluation of adult survival of Black-headed gulls

482 (Larus ridibundus) in presence of recapture heterogeneity. - Auk 115: 85-95.

483 Prévot-Julliard, A.C. et al. 1998b. Evidence for birth-site tenacity in breeding Common black484 headed gulls Larus ridibundus. - Can. J. Zool. 76: 2295-2298.

485 Pugesek, B.H. et al. 1995. Mark-resighting analysis of a California gull population. - J. Appl. $486 \quad$ Stat. 22: 625-39.

487 Rao, C.R. 1973. Linear statistical inference and its applications. - Wiley, New York

488 Regehr, E.V. et al. 2007. Effects of earlier sea ice breakup on survival and population size of 489 Polar Bear in Western Hudson Bay. - J. Wildlife Manage. 71: 2673-2683.

490 Rouan, L. et al. 2009. A general framework for modeling memory in Capture-Recapture data. $491 \quad$ J. Agric. Biol. Envir. S. In press.

492 Royle, J.A. 2008. Modeling individual effects in the Cormack-Jolly-Seber model: a state493 space formulation. - Biometrics 64: 364-370.

494 Schaub, M. et al. 2004. Estimating survival and temporary emigration in the multistate 495 capture-recapture framework. - Ecology 85: 2107-2113.

496 Schwarz, C.J. et al. 1993. Estimating migration rates using tag-recovery data. - Biometrics 497 49: 177-193.

498 Switzer, P.V. 1997. Past reproductive success affects future habitat selection. - Behav. Ecol. $499 \quad$ Sociobiol. 40: 307-312.

500 van de Pol, M. and Verhulst, S. 2006. Age-dependant traits: a new statistical model to 501 separate within- and between-individual traits. - Am. Nat. 167: 766-773. 
502 Vaupel, J.W. and Yashin, A.I. 1985. Heterogeneity's ruses: some surprising effects of

503 selection on population dynamics. - Am. Stat. 39: 176-185.

504 Whitehead, H. and Wimmer, T. 2005. Heterogeneity and the mark-recapture assessment of

505 the Scotian Shelf population of northern bottlenose whales (Hyperoodon ampullatus).-

506 Can. J. Fish. Aquat. Sci. 62: 2573-2585.

507 Wolf, M. van Doorn, G. S. Leimar, O. et al. 2007. Life-history trade-offs favour the evolution

508 of animal personalities. - Nature 447: 581-584.

509 Zens, M.S. and Peart, D.R. 2003. Dealing with death data: individual hazards, mortality and 510 bias. - Trends Ecol. Evol. 18: 366-373. 


\section{Supplementary material}

513 The following supplementary material is available for this article.

$514 \quad$ Appendix S1. Model description

$515 \quad$ Appendix S2. Simulation study

516 
518 Tables

Table 1: Components of an approximate goodness-of-fit (GOF) test for a model with

520 heterogeneity, obtained by removing from the components of the standard GOF test for the

521 time-dependent model the squared directional test statistics (see methods). The overall GOF

522 test shows no sign of lack-of-fit for a model correcting transience and trap-happiness. $d f$ is the degree of freedom. $\hat{c}$ is the overdispersion coefficient computed as the ratio between the chi-

524 squared statistic and the degree of freedom.

525

Test3: transience

Test2: trap dependence Total

\begin{tabular}{|c|c|c|c|c|c|c|}
\hline & Chi- & Squared & Chi- & Squared & Chi- \\
\hline & & squared & directional & squared & directional & squared \\
\hline & & statistic & statistic & statistic & statistic & statistic \\
\hline \multirow[t]{4}{*}{ Time-dependent model } & & 64.19 & 38.67 & 25.88 & 9.21 & 164.39 \\
\hline & df & 22 & 1 & 22 & 1 & 131 \\
\hline & P-level & $<0.0001$ & $<0.0001$ & 0.26 & 0.002 & 0.02 \\
\hline & $\hat{\mathrm{c}}$ & 2.92 & & 1.18 & & 1.25 \\
\hline
\end{tabular}

Time-dependent model with

25.52

16.67

116.52

heterogeneity of detection

$\begin{array}{rccc}\text { df } & 21 & 21 & 129 \\ \text { P-level } & 0.23 & 0.73 & 0.78 \\ \text { c } & 1.22 & 0.79 & 0.90\end{array}$


Péron et al.

Table 2: Model selection. The 16 candidate models vary in the presence/absence (Y/N)

529 of heterogeneity and of the age-effect on survival. For each model the number of parameters

530 ( $n p)$, deviance ( $D e v)$, AIC and AIC-weight are given. Subscripts $H$ and $O$ referred to models

531 with and without heterogeneity in survival (denoted $S$ ), detection (denoted $D$ ) and emigration

532 (denoted $E$ ) probabilities, while subscripts $a$ and $\bar{a}$ referred to models with and without age-

533 effect on survival. The models are sorted by AIC.

Age-

AIC

model

Heterogeneity in:

effect np Dev

AIC

weight

Survival Detection Emigration

\begin{tabular}{|c|c|c|c|c|c|c|c|c|}
\hline$\left\{\mathrm{S}_{0+\mathrm{a}} ; \mathrm{D}_{\mathrm{H}} ; \mathrm{E}_{\mathrm{H}}\right\}$ & $\mathrm{N}$ & $\mathrm{Y}$ & $\mathrm{Y}$ & $\mathrm{Y}$ & 43 & 7781.88 & 7867.88 & 0.761 \\
\hline$\left\{\mathrm{S}_{0+\overline{\mathrm{a}}} ; \mathrm{D}_{\mathrm{H}} ; \mathrm{E}_{0}\right\}$ & $\mathrm{N}$ & $\mathrm{Y}$ & $\mathrm{N}$ & $\mathrm{N}$ & 36 & 7799.44 & 7871.44 & 0.128 \\
\hline$\left\{\mathrm{S}_{\mathrm{H}+\mathrm{a}} ; \mathrm{D}_{\mathrm{H}} ; \mathrm{E}_{0}\right\}$ & $\mathrm{Y}$ & $\mathrm{Y}$ & $\mathrm{N}$ & $\mathrm{Y}$ & 47 & 7779.50 & 7873.50 & 0.046 \\
\hline$\left\{\mathrm{S}_{\mathrm{H}+\overline{\mathrm{a}}} ; \mathrm{D}_{0} ; \mathrm{E}_{0}\right\}$ & $\mathrm{Y}$ & $\mathrm{N}$ & $\mathrm{N}$ & $\mathrm{N}$ & 35 & 7803.62 & 7873.62 & 0.043 \\
\hline$\left\{\mathrm{S}_{0+\mathrm{a}} ; \mathrm{D}_{0} ; \mathrm{E}_{\mathrm{H}}\right\}$ & $\mathrm{N}$ & $\mathrm{N}$ & $\mathrm{Y}$ & $\mathrm{Y}$ & 37 & 7802.12 & 7876.12 & 0.012 \\
\hline$\left\{\mathrm{S}_{\mathrm{H}+\mathrm{a}} ; \mathrm{D}_{0} ; \mathrm{E}_{0}\right\}$ & $\mathrm{Y}$ & $\mathrm{N}$ & $\mathrm{N}$ & $\mathrm{Y}$ & 38 & 7801.99 & 7877.99 & 0.005 \\
\hline$\left\{\mathrm{S}_{0+\overline{\mathrm{a}}} ; \mathrm{D}_{\mathrm{H}} ; \mathrm{E}_{\mathrm{H}}\right\}$ & $\mathrm{N}$ & $\mathrm{Y}$ & $\mathrm{Y}$ & $\mathrm{N}$ & 40 & 7800.28 & 7880.28 & 0.002 \\
\hline$\left\{\mathrm{S}_{0+\mathrm{a}} ; \mathrm{D}_{\mathrm{H}} ; \mathrm{E}_{0}\right\}$ & $\mathrm{N}$ & $\mathrm{Y}$ & $\mathrm{N}$ & $\mathrm{Y}$ & 41 & 7797.91 & 7879.91 & 0.002 \\
\hline$\left\{\mathrm{S}_{\mathrm{H}+\mathrm{a}} ; \mathrm{D}_{0} ; \mathrm{E}_{\mathrm{H}}\right\}$ & $\mathrm{Y}$ & $\mathrm{N}$ & $\mathrm{Y}$ & $\mathrm{Y}$ & 42 & 7797.25 & 7881.25 & 0.001 \\
\hline$\left\{\mathrm{S}_{\mathrm{H}+\mathrm{a}} ; \mathrm{D}_{\mathrm{H}} ; \mathrm{E}_{\mathrm{H}}\right\}$ & $\mathrm{Y}$ & $\mathrm{Y}$ & $\mathrm{Y}$ & Y & 53 & 7777.12 & 7883.12 & 0.000 \\
\hline$\left\{\mathrm{S}_{\mathrm{H}+\overline{\mathrm{a}}} ; \mathrm{D}_{\mathrm{H}} ; \mathrm{E}_{0}\right\}$ & $\mathrm{Y}$ & $\mathrm{Y}$ & $\mathrm{N}$ & $\mathrm{N}$ & 43 & 7802.21 & 7888.21 & 0.000 \\
\hline$\left\{\mathrm{S}_{0+\overline{\mathrm{a}}} ; \mathrm{D}_{0} ; \mathrm{E}_{0}\right\}$ & $\mathrm{N}$ & $\mathrm{N}$ & $\mathrm{N}$ & $\mathrm{N}$ & 31 & 7856.10 & 7918.10 & 0.000 \\
\hline$\left\{\mathrm{S}_{0+\mathrm{a}} ; \mathrm{D}_{0} ; \mathrm{E}_{0}\right\}$ & $\mathrm{N}$ & $\mathrm{N}$ & $\mathrm{N}$ & $\mathrm{Y}$ & 34 & 7820.42 & 7888.42 & 0.000 \\
\hline$\left\{\mathrm{S}_{\mathrm{H}+\overline{\mathrm{a}}} ; \mathrm{D}_{0} ; \mathrm{E}_{\mathrm{H}}\right\}$ & $\mathrm{Y}$ & $\mathrm{N}$ & $\mathrm{Y}$ & $\mathrm{N}$ & 37 & 7852.13 & 7926.13 & 0.000 \\
\hline$\left\{\mathrm{S}_{\mathrm{H}+\overline{\mathrm{a}}} ; \mathrm{D}_{\mathrm{H}} ; \mathrm{E}_{\mathrm{H}}\right\}$ & $\mathrm{Y}$ & $\mathrm{Y}$ & $\mathrm{Y}$ & $\mathrm{N}$ & 49 & 7834.15 & 7932.15 & 0.000 \\
\hline$\left\{\mathrm{S}_{0+\overline{\mathrm{a}}} ; \mathrm{D}_{0} ; \mathrm{E}_{\mathrm{H}}\right\}$ & $\mathrm{N}$ & $\mathrm{N}$ & $\mathrm{Y}$ & $\mathrm{N}$ & 34 & 7857.33 & 7925.33 & 0.000 \\
\hline
\end{tabular}


Figure legend

Fig. 1: Example heterogeneous population where the average survival rate is not representative of the true ageing processes. This example population consists of $10 \%$ of "initially robust" individuals and $90 \%$ of "initially weak" individuals, each subpopulation experiencing the same slow decrease in survival with age. (a) Age variation in the true survival rate for the two subpopulations (grey lines) and in the average survival rate for the population (black line). (b) Age variation in the proportion of robust individuals.

Fig. 2: A tree diagram describing the hidden Markov chain probability structure for a model with a two-class individual heterogeneity structure on survival probabilities, the possibility to temporarily emigrate, and a detailed observation structure for the breeding probability; S2: alive in the study site with low survival probability; AE1: alive outside the study site with high survival probability; AE2: alive outside the study site with low survival

550 probability; dead), while grey boxes represent the 3 possible observations following initial release (0: not seen, 1: seen and breeding status confirmed; 2: seen but breeding status not confirmed). The probability for observing a particular encounter history is obtained by summing the probability of all possible paths leading to a given encounter history (for the 554 sake of clarity at time $\mathrm{t}+1$ only the states "AE" are represented; paths from states " $\mathrm{S}$ " are the 555 same as at time $t$ and the state "dead" is absorbing, i.e. there is no path out of it). The 556 probability of a given path can be obtained by multiplying the probabilities appearing 557 alongside its component arrows. These probabilities consist of functions of $\pi$, the initial state 558 probabilities; $\varphi$, apparent survival probabilities; $\psi$, state transition probabilities; $\mathrm{p}$, detection 
559 probabilities; and $r$, the probabilities to confirm breeding status. A more formal matrix

560 description of the same model is provided in Table 1.

561

562 Fig. 3: Survival probabilities for the Black-headed gulls as a function of true age.

563 Parameters estimates are from model $\left\{\mathrm{S}_{0+\mathrm{a}} ; \mathrm{D}_{\mathrm{H}} ; \mathrm{E}_{\mathrm{H}}\right\}$ which includes heterogeneity in both

564 detection and emigration probabilities, and a piecewise constrained relationship between age

565 and survival probabilities. Dotted lines correspond to the $95 \%$ asymptotic confidence interval.

566 Black dots are boundary estimates, which come with no standard errors. The survival

567 probability for the first age class (age 2) was estimated separately and fell on the line for older 568 age classes. 


\section{FIGURE}

$571 \quad$ Figure 1
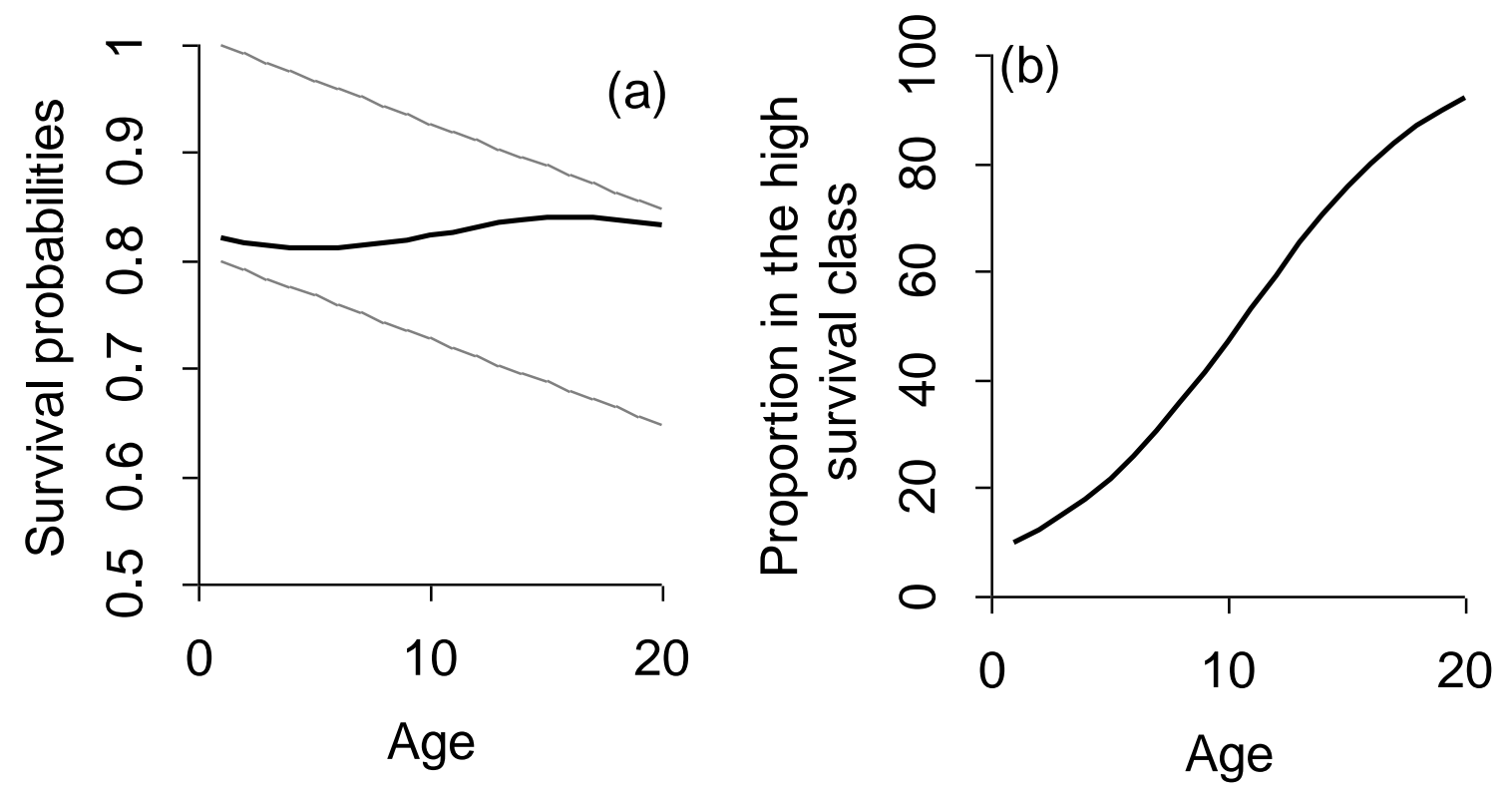

572

573 
Péron et al.

p. 31

\section{Figure 2}
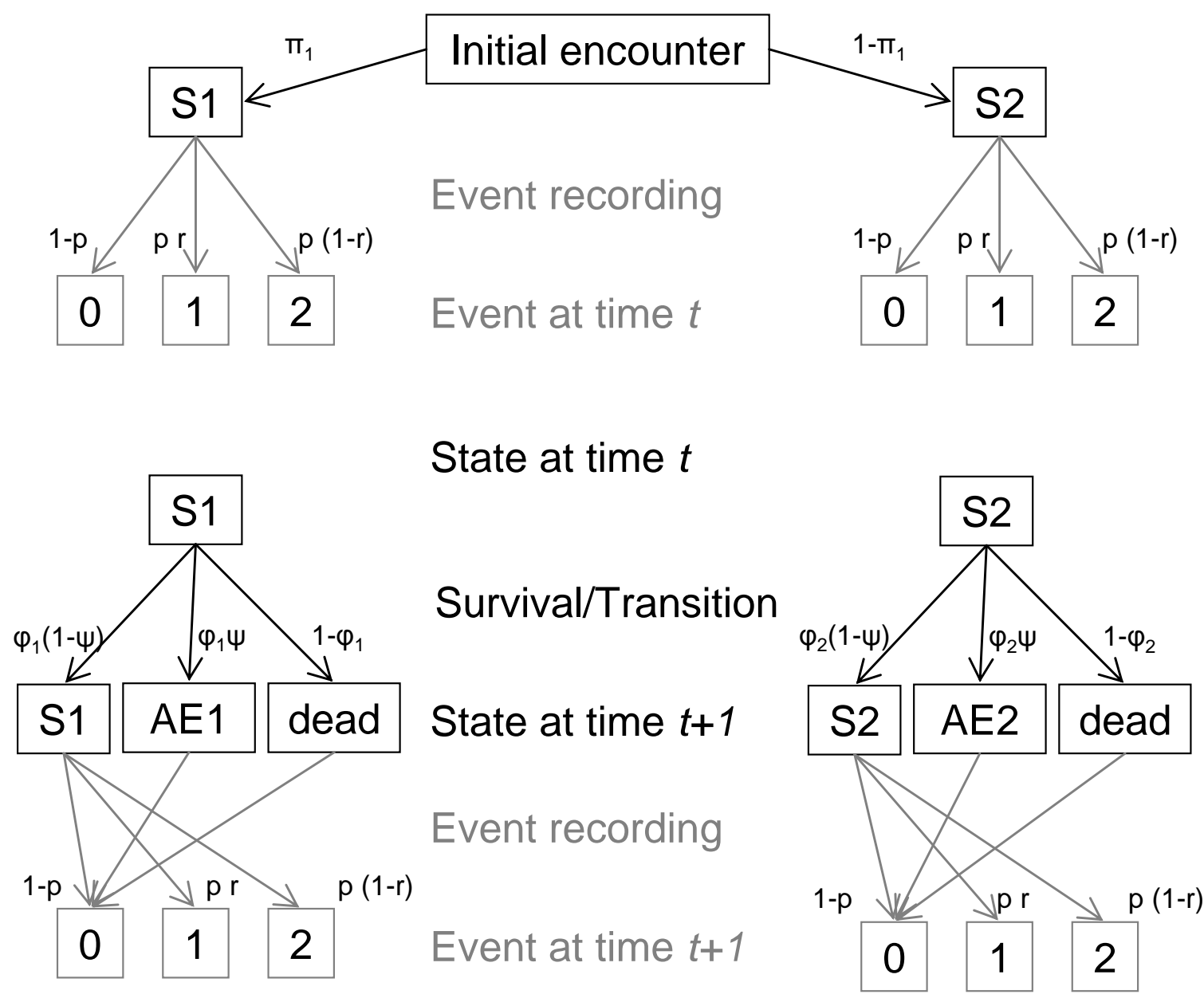

State at time $t+1$

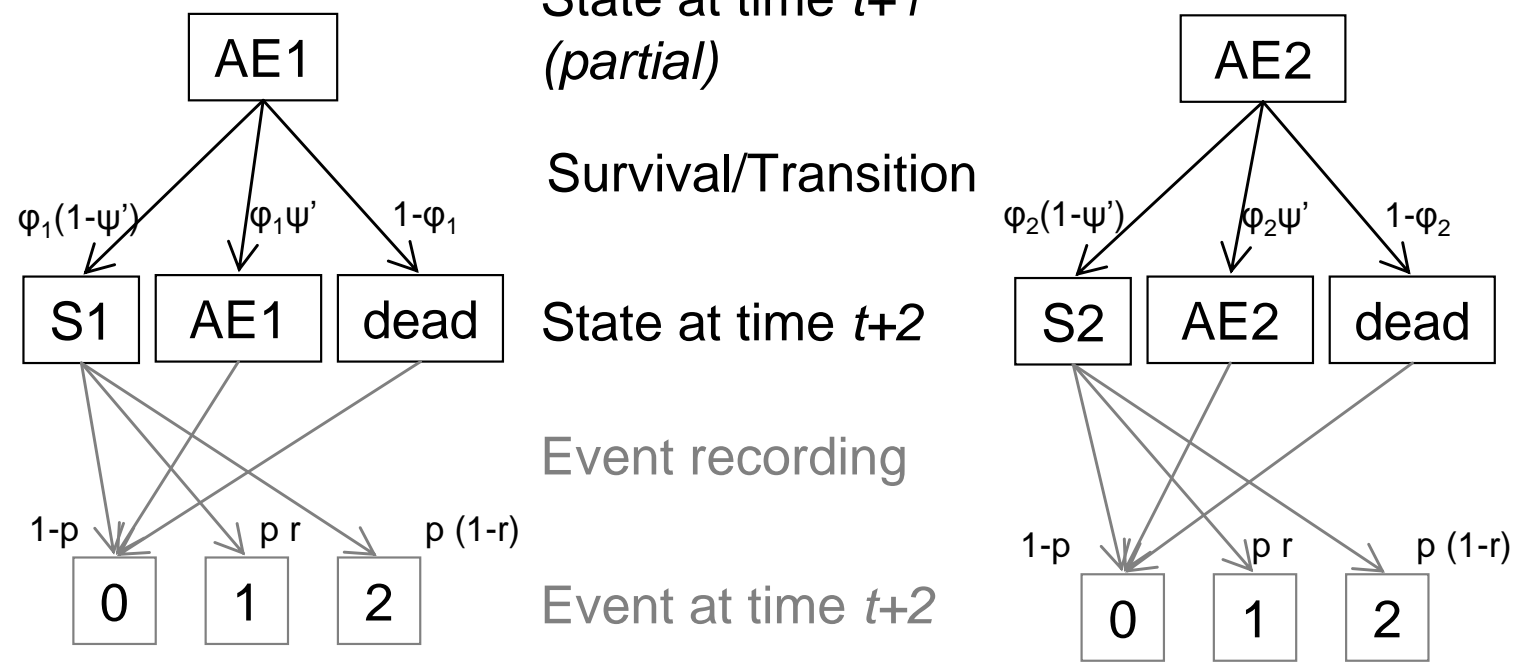


Péron et al.

p. 32

581

582

583

584 Figure 3

585

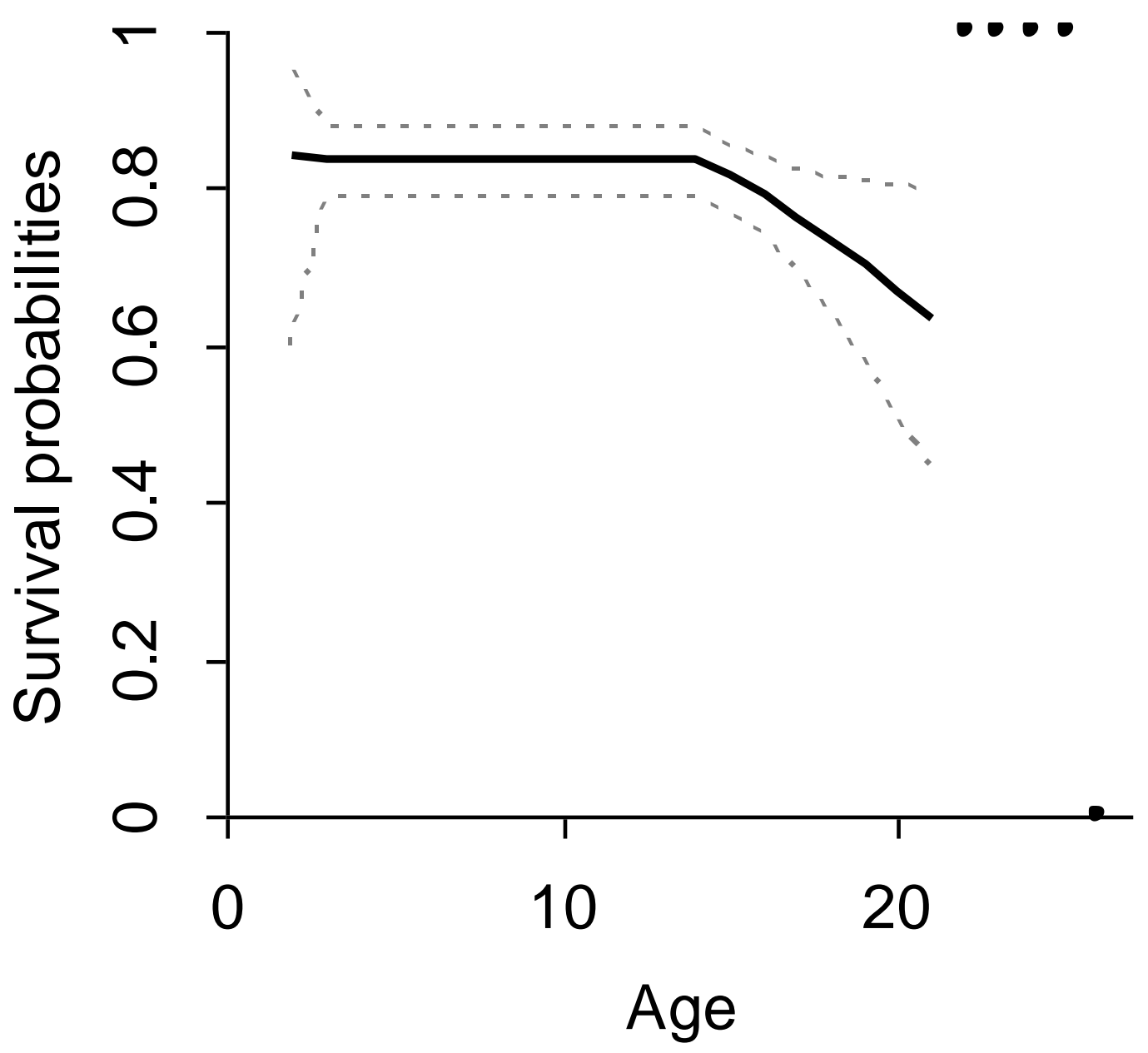

586

587

588 


\section{Part 1.Individual heterogeneity in multievent models}

There were $2^{k}$ observable states ( $k$ being the number of parameters types affected by heterogeneity in the model), plus one or two AE-states depending on the presence of survival

594 heterogeneity in the model, and the state dead. We describe in this appendix two of the 595 considered models: (i) the model $\left\{\mathrm{S}_{\mathrm{H}} ; \mathrm{E}_{0} ; \mathrm{D}_{0}\right\}$ including heterogeneity in survival 596 probabilities only $\left(2^{1}+2+1=5\right.$ states; part 3$)$ and (ii) the model $\left\{\mathrm{S}_{\mathrm{H}} ; \mathrm{E}_{\mathrm{H}} ; \mathrm{D}_{\mathrm{H}}\right\}$ including the 597 three kinds of heterogeneity (survival, detection and emigration: $2^{3}+2+1=11$ states; part 4). When considering detection heterogeneity, we did not allow individuals to move between high- and low-detection classes, based on the finding that individuals tend to be site-

600 faithful on a small scale when breeding in LR (Prévot-Julliard et al. 1998b). However, when a 601 bird emigrated, the model did not keep memory of its previous classes of detection and 602 emigration, letting it free to change either of these classes upon return. The model permitted 603 returning individuals to settle in a different zone of the pond or to change of dispersal 604 behaviour. 


\section{Part 2.Parameterisation}

The complex model structure rendered necessary the use of some constraints on the

609 parameters. These and the effects that were considered in the model selection procedure are

610 presented below:

\section{1) - Initial proportions}

The $\Pi$-vector represents the probability of being in the different classes of

613 heterogeneity at first detection. We assumed that $\Pi$ was constant over time, hence assuming

614 that the proportions of the different classes of heterogeneity did not vary over time. age, there might have been identifiabilities issues because high-survival individuals entering the dataset at old age do have a low survival indeed.

\section{2) - Dispersal probabilities}

Dispersal probabilities were modelled as constant over time, for parsimony and because parameter identifiability required that the probability of returning from the unobservable state to the study colony was kept constant over time and that the survival probabilities were the same in the states $\mathrm{AE}$ and in the states available for detection (Fujiwara and Caswell 2002). Heterogeneity in emigration probability was modelled in a fashion similar to "mover-stayer models" that consider a class with high site-tenacity and a "volatile" class

627 (Goodman 1961). Once in the state AE, individual lost their classification as low/high

628 detection and low/high emigration. Therefore, after emigration, they could become more 
630

631

632

633

634

635

636

637

638

639

640

641

642

644

645

646

647

648

649

650

651

652

653

\section{3) - Detection probabilities}

The matrix of the probabilities of being detected when alive and present on the study site $(\mathrm{P})$ was modelled as time-dependent to fit with the known variation in resighting effort over years (Prévot-Julliard et al. 1998a). Heterogeneity was modelled in a fashion additive to time. Given the high small-scale site fidelity exhibited by breeders within the study colony (Prévot-Julliard et al. 1998b), exchanges between detection classes were expected to be low and we chose not to allow for direct transitions between heterogeneity classes. Indirect transitions were possible after temporary emigration.

\section{4) - Breeding status confirmation probabilities}

They were modelled as constant over time in order to keep parsimonious. Indeed, if detection probabilities varied with time because of between-year variation in detection effort, breeding status confirmation probabilities were supposedly more related to the configuration of the colony (distribution of the roost sites, density of the vegetation), and could be considered time-invariant in a first approach. If there was heterogeneity in detection probabilities in the model considered, breeding status confirmation probability was modelled as depending on detectability.

\section{5) - Survival probabilities: modelling age-effect}

We considered the age-effect on survival as being additive (on a logit scale) to the heterogeneity level, if any.

Models with a complete age-effect (age or TFC treated as categorical variables: 29

levels in our case) are the straightforward way to model age-dependency on survival because they make no hypothesis on the shape of that dependency. However, studying the strength of senescence requires the estimation of a slope describing the decrease in survival probabilities with age (Jones et al. 2008), something that can be computed using age or TFC as a 
654

continuous variable in a constrained log-linear relationship that moreover reduces the number of parameters in the model (e.g. Loison et al. 1999; Nichols et al. 1997).

However, the sparseness of data at old ages (only 14 individuals were observed at an age $\geq 22$, of which none was seen after age 25 ) renders maximum likelihood estimators unstable, and produces boundary survival estimates (boundary estimates are age-specific survival probabilities that are estimated at 0 or 1 because of low sample size). For example, the occasional individual who will survive 1 year after the others will induce a survival probability of 1 at that age. These boundary estimates are likely to hamper the accurate detection and estimation of the strength of survival senescence, particularly when using constrained regressions (Jones et al. 2008). We first ran a model with complete age-effect, and it appeared that the age-threshold after which boundary estimates were an issue was 22 . Boundary estimates were excluded from the constrained relationship presented below. From age 1 to 22, age-dependency was modelled using a three-parameter piecewise relationship. Age one had a separate survival estimate (because we expected it to be lower; e.g. Pugesek et al. 1995 in a related species). Then, we modelled a plateau that lasted up to an age-threshold (which is species-specific: Jones et al. 2008). It was estimated to be 14-year old in black-headed gull by mean of life-history comparisons (G.P. et al. unpublished results); in other Larid species, the threshold was found around 14 years in Larus californicus (Pugesek et al. 1995) and between 13 and 16 in Rissa tridactyla (Aebischer and Coulson 1990; Frederiksen et al. 2004). Afterwards we modelled a logit-linear decline in survival probabilities (Loison et al. 1999).

\section{6) - Implementation of true age in CMR models when first capture occurs at a varying age}

True age (as opposed to TFC, see main text) was implemented with a computer intensive procedure. E-SURGE uses the GEMACO syntax to constrain the parameters. The phrase required for modelling the dependency of CMR parameters on true age, when 
Péron et al.

679

680

681

682

683

684

685

686

687

688

689

690

691

692

693

694

695

696

697

698

699

700

701

702

703

704

705

706

707

708

709

710

711

712

713

714

715

716

717

individuals enter the dataset at various ages, was based upon the use of groups. Individuals entering the dataset at age $A$ were in the $A^{\text {th }}$ group. In the $A^{\text {th }}$ group at the $\mathrm{t}^{\text {th }}$ session after their first observation, individuals had the age $\mathrm{A}+\mathrm{t}$. The syntax for this relationship, to be entered in GEMACO, is started below:

$$
\{\mathrm{g}(1) \cdot \mathrm{a}(1) \quad+\quad \mathrm{g}(1) \cdot \mathrm{a}(2) \& \mathrm{~g}(2) \cdot \mathrm{a}(1) \quad+\quad \mathrm{g}(1) \cdot \mathrm{a}(3) \& \mathrm{~g}(2) \cdot \mathrm{a}(2) \& \mathrm{~g}(3) \cdot \mathrm{a}(1)+\ldots
$$

age1 age 2 age3

Further details can be found in (Choquet 2008). We provide below a short and flexible R-program (R Project Core Team 2008) that generates this syntax for any number of age classes:

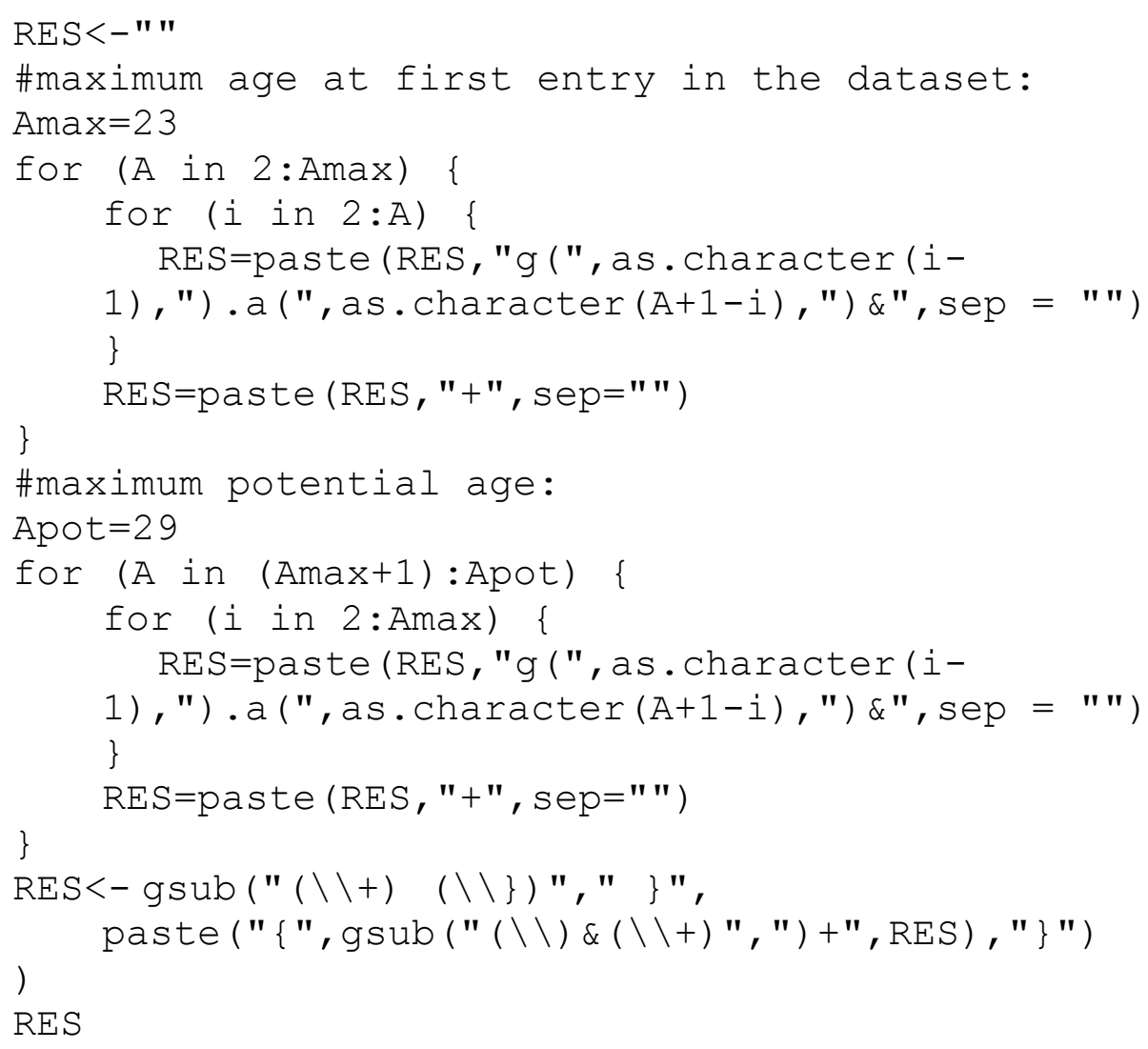

With the values 23 and 29 for Amax and Apot (these values correspond to the black-

headed gull dataset), we obtained the following sentence to be entered as a shortcut for True

Age in GEMACO:

$\{\mathrm{g}(1) \cdot \mathrm{a}(1)+\mathrm{g}(1) \cdot \mathrm{a}(2) \& \mathrm{~g}(2) \cdot \mathrm{a}(1)+\mathrm{g}(1) \cdot \mathrm{a}(3) \& \mathrm{~g}(2) \cdot \mathrm{a}(2) \& \mathrm{~g}(3) \cdot \mathrm{a}(1)+\mathrm{g}(1) \cdot \mathrm{a}(4) \& \mathrm{~g}(2) \cdot \mathrm{a}(3) \& \mathrm{~g}(3) \cdot \mathrm{a}(2) \& \mathrm{~g}(4) \cdot \mathrm{a}(1)+\mathrm{g}(1) \cdot \mathrm{a}$ (5)\&g(2) $\cdot \mathrm{a}(4) \& g(3) \cdot \mathrm{a}(3) \& \mathrm{~g}(4) \cdot \mathrm{a}(2) \& \mathrm{~g}(5) \cdot \mathrm{a}(1)+\mathrm{g}(1) \cdot \mathrm{a}(6) \& \mathrm{~g}(2) \cdot \mathrm{a}(5) \& \mathrm{~g}(3) \cdot \mathrm{a}(4) \& \mathrm{~g}(4) \cdot \mathrm{a}(3) \& \mathrm{~g}(5) \cdot \mathrm{a}(2) \& \mathrm{~g}(6) \cdot \mathrm{a}(1)+\mathrm{g}$ (1).a(7)\&g(2).a(6)\&g(3).a(5)\&g(4).a(4)\&g(5).a(3)\&g(6).a(2)\&g(7).a(1)+g(1).a(8)\&g(2).a(7)\&g(3).a(6)\&g(4) $a($ 
5) $\& \mathrm{~g}(5) \cdot \mathrm{a}(4) \& \mathrm{~g}(6) \cdot \mathrm{a}(3) \& \mathrm{~g}(7) \cdot \mathrm{a}(2) \& \mathrm{~g}(8) \cdot \mathrm{a}(1)+\mathrm{g}(1) \cdot \mathrm{a}(9) \& \mathrm{~g}(2) \cdot \mathrm{a}(8) \& \mathrm{~g}(3) \cdot \mathrm{a}(7) \& \mathrm{~g}(4) \cdot \mathrm{a}(6) \& \mathrm{~g}(5) \cdot \mathrm{a}(5) \& \mathrm{~g}(6) \cdot \mathrm{a}(4) \& \mathrm{~g}($ 7) $a(3) \& g(8) \cdot a(2) \& g(9) \cdot a(1)+g(1) \cdot a(10) \& g(2) \cdot a(9) \& g(3) \cdot a(8) \& g(4) \cdot a(7) \& g(5) \cdot a(6) \& g(6) \cdot a(5) \& g(7) \cdot a(4) \& g(8) \cdot a($ $3) \& g(9) \cdot a(2) \& g(10) \cdot a(1)+g(1) \cdot a(11) \& g(2) \cdot a(10) \& g(3) \cdot a(9) \& g(4) \cdot a(8) \& g(5) \cdot a(7) \& g(6) \cdot a(6) \& g(7) \cdot a(5) \& g(8) \cdot a(4)$ $\& \mathrm{~g}(9) \cdot \mathrm{a}(3) \& \mathrm{~g}(10) \cdot \mathrm{a}(2) \& \mathrm{~g}(11) \cdot \mathrm{a}(1)+\mathrm{g}(1) \cdot \mathrm{a}(12) \& \mathrm{~g}(2) \cdot \mathrm{a}(11) \& \mathrm{~g}(3) \cdot \mathrm{a}(10) \& \mathrm{~g}(4) \cdot \mathrm{a}(9) \& \mathrm{~g}(5) \cdot \mathrm{a}(8) \& \mathrm{~g}(6) \cdot \mathrm{a}(7) \& \mathrm{~g}(7) \cdot \mathrm{a}(6)$ $\& \mathrm{~g}(8) . \mathrm{a}(5) \& \mathrm{~g}(9) \cdot \mathrm{a}(4) \& \mathrm{~g}(10) . \mathrm{a}(3) \& \mathrm{~g}(11) \cdot \mathrm{a}(2) \& \mathrm{~g}(12) \cdot \mathrm{a}(1)+\mathrm{g}(1) \cdot \mathrm{a}(13) \& \mathrm{~g}(2) \cdot \mathrm{a}(12) \& \mathrm{~g}(3) \cdot \mathrm{a}(11) \& \mathrm{~g}(4) \cdot \mathrm{a}(10) \& \mathrm{~g}(5) \cdot \mathrm{a}$ (9) $\& \mathrm{~g}(6) \cdot \mathrm{a}(8) \& \mathrm{~g}(7) \cdot \mathrm{a}(7) \& \mathrm{~g}(8) \cdot \mathrm{a}(6) \& \mathrm{~g}(9) \cdot \mathrm{a}(5) \& \mathrm{~g}(10) \cdot \mathrm{a}(4) \& \mathrm{~g}(11) \cdot \mathrm{a}(3) \& \mathrm{~g}(12) \cdot \mathrm{a}(2) \& \mathrm{~g}(13) \cdot \mathrm{a}(1)+\mathrm{g}(1) \cdot \mathrm{a}(14) \& \mathrm{~g}(2) \cdot \mathrm{a}$ (13) $\& g(3) . a(12) \& g(4) \cdot a(11) \& g(5) \cdot a(10) \& g(6) \cdot a(9) \& g(7) \cdot a(8) \& g(8) \cdot a(7) \& g(9) \cdot a(6) \& g(10) \cdot a(5) \& g(11) \cdot a(4) \& g(1$ 2). $a(3) \& g(13) \cdot a(2) \& g(14) \cdot a(1)+g(1) \cdot a(15) \& g(2) \cdot a(14) \& g(3) \cdot a(13) \& g(4) \cdot a(12) \& g(5) \cdot a(11) \& g(6) \cdot a(10) \& g(7) \cdot a(9)$ $\& \mathrm{~g}(8) \cdot \mathrm{a}(8) \& \mathrm{~g}(9) \cdot \mathrm{a}(7) \& \mathrm{~g}(10) \cdot \mathrm{a}(6) \& \mathrm{~g}(11) \cdot \mathrm{a}(5) \& \mathrm{~g}(12) \cdot \mathrm{a}(4) \& \mathrm{~g}(13) \cdot \mathrm{a}(3) \& \mathrm{~g}(14) \cdot \mathrm{a}(2) \& \mathrm{~g}(15) \cdot \mathrm{a}(1)+\mathrm{g}(1) \cdot \mathrm{a}(16) \& \mathrm{~g}(2) \cdot \mathrm{a}$ (15) $\& \mathrm{~g}(3) \cdot \mathrm{a}(14) \& \mathrm{~g}(4) \cdot \mathrm{a}(13) \& \mathrm{~g}(5) \cdot \mathrm{a}(12) \& \mathrm{~g}(6) \cdot \mathrm{a}(11) \& \mathrm{~g}(7) \cdot \mathrm{a}(10) \& \mathrm{~g}(8) \cdot \mathrm{a}(9) \& \mathrm{~g}(9) \cdot \mathrm{a}(8) \& \mathrm{~g}(10) \cdot \mathrm{a}(7) \& \mathrm{~g}(11) \cdot \mathrm{a}(6) \& \mathrm{~g}$ (12) $\mathrm{a}(5) \& \mathrm{~g}(13) \cdot \mathrm{a}(4) \& \mathrm{~g}(14) \cdot \mathrm{a}(3) \& \mathrm{~g}(15) \cdot \mathrm{a}(2) \& \mathrm{~g}(16) \cdot \mathrm{a}(1)+\mathrm{g}(1) \cdot \mathrm{a}(17) \& \mathrm{~g}(2) \cdot \mathrm{a}(16) \& \mathrm{~g}(3) \cdot \mathrm{a}(15) \& \mathrm{~g}(4) \cdot \mathrm{a}(14) \& \mathrm{~g}(5) \cdot \mathrm{a}($ 13) $\& \mathrm{~g}(6) \cdot \mathrm{a}(12) \& \mathrm{~g}(7) \cdot \mathrm{a}(11) \& \mathrm{~g}(8) \cdot \mathrm{a}(10) \& \mathrm{~g}(9) \cdot \mathrm{a}(9) \& \mathrm{~g}(10) \cdot \mathrm{a}(8) \& \mathrm{~g}(11) \cdot \mathrm{a}(7) \& \mathrm{~g}(12) \cdot \mathrm{a}(6) \& \mathrm{~g}(13) \cdot \mathrm{a}(5) \& \mathrm{~g}(14) \cdot \mathrm{a}(4) \& \mathrm{~g}$ (15). $\mathrm{a}(3) \& \mathrm{~g}(16) \cdot \mathrm{a}(2) \& \mathrm{~g}(17) \cdot \mathrm{a}(1)+\mathrm{g}(1) \cdot \mathrm{a}(18) \& \mathrm{~g}(2) \cdot \mathrm{a}(17) \& \mathrm{~g}(3) \cdot \mathrm{a}(16) \& \mathrm{~g}(4) \cdot \mathrm{a}(15) \& \mathrm{~g}(5) \cdot \mathrm{a}(14) \& \mathrm{~g}(6) \cdot \mathrm{a}(13) \& \mathrm{~g}(7) \cdot \mathrm{a}($ 12) $\& \mathrm{~g}(8) \cdot \mathrm{a}(11) \& \mathrm{~g}(9) \cdot \mathrm{a}(10) \& \mathrm{~g}(10) \cdot \mathrm{a}(9) \& \mathrm{~g}(11) \cdot \mathrm{a}(8) \& \mathrm{~g}(12) \cdot \mathrm{a}(7) \& \mathrm{~g}(13) \cdot \mathrm{a}(6) \& \mathrm{~g}(14) \cdot \mathrm{a}(5) \& \mathrm{~g}(15) \cdot \mathrm{a}(4) \& \mathrm{~g}(16) \cdot \mathrm{a}(3) \&$ $\mathrm{g}(17) \cdot \mathrm{a}(2) \& \mathrm{~g}(18) \cdot \mathrm{a}(1)+\mathrm{g}(1) \cdot \mathrm{a}(19) \& \mathrm{~g}(2) \cdot \mathrm{a}(18) \& \mathrm{~g}(3) \cdot \mathrm{a}(17) \& \mathrm{~g}(4) \cdot \mathrm{a}(16) \& \mathrm{~g}(5) \cdot \mathrm{a}(15) \& \mathrm{~g}(6) \cdot \mathrm{a}(14) \& \mathrm{~g}(7) \cdot \mathrm{a}(13) \& \mathrm{~g}(8)$. $\mathrm{a}(12) \& \mathrm{~g}(9) \cdot \mathrm{a}(11) \& \mathrm{~g}(10) \cdot \mathrm{a}(10) \& \mathrm{~g}(11) \cdot \mathrm{a}(9) \& \mathrm{~g}(12) \cdot \mathrm{a}(8) \& \mathrm{~g}(13) \cdot \mathrm{a}(7) \& \mathrm{~g}(14) \cdot \mathrm{a}(6) \& \mathrm{~g}(15) \cdot \mathrm{a}(5) \& \mathrm{~g}(16) \cdot \mathrm{a}(4) \& \mathrm{~g}(17) \cdot \mathrm{a}($ 3) $\& \mathrm{~g}(18) \cdot \mathrm{a}(2) \& \mathrm{~g}(19) \cdot \mathrm{a}(1)+\mathrm{g}(1) \cdot \mathrm{a}(20) \& \mathrm{~g}(2) \cdot \mathrm{a}(19) \& \mathrm{~g}(3) \cdot \mathrm{a}(18) \& \mathrm{~g}(4) \cdot \mathrm{a}(17) \& \mathrm{~g}(5) \cdot \mathrm{a}(16) \& \mathrm{~g}(6) \cdot \mathrm{a}(15) \& \mathrm{~g}(7) \cdot \mathrm{a}(14) \& \mathrm{~g}$ (8). $a(13) \& g(9) \cdot a(12) \& g(10) . a(11) \& g(11) . a(10) \& g(12) . a(9) \& g(13) \cdot a(8) \& g(14) \cdot a(7) \& g(15) \cdot a(6) \& g(16) . a(5) \& g(1$ 7). $a(4) \& g(18) . a(3) \& g(19) \cdot a(2) \& g(20) \cdot a(1)+g(1) \cdot a(21) \& g(2) \cdot a(20) \& g(3) \cdot a(19) \& g(4) \cdot a(18) \& g(5) \cdot a(17) \& g(6) \cdot a(1$ 6) $\& \mathrm{~g}(7) \cdot \mathrm{a}(15) \& \mathrm{~g}(8) \cdot \mathrm{a}(14) \& \mathrm{~g}(9) \cdot \mathrm{a}(13) \& \mathrm{~g}(10) \cdot \mathrm{a}(12) \& \mathrm{~g}(11) \cdot \mathrm{a}(11) \& \mathrm{~g}(12) \cdot \mathrm{a}(10) \& \mathrm{~g}(13) \cdot \mathrm{a}(9) \& \mathrm{~g}(14) \cdot \mathrm{a}(8) \& \mathrm{~g}(15) \cdot \mathrm{a}(7$ ) $\& \mathrm{~g}(16) \cdot \mathrm{a}(6) \& \mathrm{~g}(17) \cdot \mathrm{a}(5) \& \mathrm{~g}(18) \cdot \mathrm{a}(4) \& \mathrm{~g}(19) \cdot \mathrm{a}(3) \& \mathrm{~g}(20) \cdot \mathrm{a}(2) \& \mathrm{~g}(21) \cdot \mathrm{a}(1)+\mathrm{g}(1) \cdot \mathrm{a}(22) \& \mathrm{~g}(2) \cdot \mathrm{a}(21) \& \mathrm{~g}(3) \cdot \mathrm{a}(20) \& \mathrm{~g}($ 4). $a(19) \& g(5) . a(18) \& g(6) \cdot a(17) \& g(7) \cdot a(16) \& g(8) . a(15) \& g(9) \cdot a(14) \& g(10) \cdot a(13) \& g(11) . a(12) \& g(12) . a(11) \& g(1$ 3). $\mathrm{a}(10) \& \mathrm{~g}(14) \cdot \mathrm{a}(9) \& \mathrm{~g}(15) \cdot \mathrm{a}(8) \& \mathrm{~g}(16) \cdot \mathrm{a}(7) \& \mathrm{~g}(17) \cdot \mathrm{a}(6) \& \mathrm{~g}(18) \cdot \mathrm{a}(5) \& \mathrm{~g}(19) \cdot \mathrm{a}(4) \& \mathrm{~g}(20) \cdot \mathrm{a}(3) \& \mathrm{~g}(21) \cdot \mathrm{a}(2) \& \mathrm{~g}(22) \cdot \mathrm{a}$ (1) $+\mathrm{g}(1) \cdot \mathrm{a}(23) \& \mathrm{~g}(2) \cdot \mathrm{a}(22) \& \mathrm{~g}(3) \cdot \mathrm{a}(21) \& \mathrm{~g}(4) \cdot \mathrm{a}(20) \& \mathrm{~g}(5) \cdot \mathrm{a}(19) \& \mathrm{~g}(6) \cdot \mathrm{a}(18) \& \mathrm{~g}(7) \cdot \mathrm{a}(17) \& \mathrm{~g}(8) \cdot \mathrm{a}(16) \& \mathrm{~g}(9) \cdot \mathrm{a}(15) \&$ $\mathrm{g}(10) \cdot \mathrm{a}(14) \& \mathrm{~g}(11) \cdot \mathrm{a}(13) \& \mathrm{~g}(12) \cdot \mathrm{a}(12) \& \mathrm{~g}(13) \cdot \mathrm{a}(11) \& \mathrm{~g}(14) \cdot \mathrm{a}(10) \& \mathrm{~g}(15) \cdot \mathrm{a}(9) \& \mathrm{~g}(16) \cdot \mathrm{a}(8) \& \mathrm{~g}(17) \cdot \mathrm{a}(7) \& \mathrm{~g}(18) \cdot \mathrm{a}(6)$ $\& \mathrm{~g}(19) \cdot \mathrm{a}(5) \& \mathrm{~g}(20) \cdot \mathrm{a}(4) \& \mathrm{~g}(21) \cdot \mathrm{a}(3) \& \mathrm{~g}(22) \cdot \mathrm{a}(2)+\mathrm{g}(1) \cdot \mathrm{a}(24) \& \mathrm{~g}(2) \cdot \mathrm{a}(23) \& \mathrm{~g}(3) \cdot \mathrm{a}(22) \& \mathrm{~g}(4) \cdot \mathrm{a}(21) \& \mathrm{~g}(5) \cdot \mathrm{a}(20) \& \mathrm{~g}(6$ ). $\mathrm{a}(19) \& \mathrm{~g}(7) . \mathrm{a}(18) \& \mathrm{~g}(8) . \mathrm{a}(17) \& \mathrm{~g}(9) . \mathrm{a}(16) \& \mathrm{~g}(10) . \mathrm{a}(15) \& \mathrm{~g}(11) \cdot \mathrm{a}(14) \& \mathrm{~g}(12) \cdot \mathrm{a}(13) \& \mathrm{~g}(13) \cdot \mathrm{a}(12) \& \mathrm{~g}(14) \cdot \mathrm{a}(11) \& \mathrm{~g}($ 15). $\mathrm{a}(10) \& \mathrm{~g}(16) \cdot \mathrm{a}(9) \& \mathrm{~g}(17) . \mathrm{a}(8) \& \mathrm{~g}(18) \cdot \mathrm{a}(7) \& \mathrm{~g}(19) \cdot \mathrm{a}(6) \& \mathrm{~g}(20) \cdot \mathrm{a}(5) \& \mathrm{~g}(21) \cdot \mathrm{a}(4) \& \mathrm{~g}(22) \cdot \mathrm{a}(3)+\mathrm{g}(1) \cdot \mathrm{a}(25) \& \mathrm{~g}(2) \cdot \mathrm{a}$ (24) $\& \mathrm{~g}(3) \cdot \mathrm{a}(23) \& \mathrm{~g}(4) \cdot \mathrm{a}(22) \& \mathrm{~g}(5) \cdot \mathrm{a}(21) \& \mathrm{~g}(6) \cdot \mathrm{a}(20) \& \mathrm{~g}(7) \cdot \mathrm{a}(19) \& \mathrm{~g}(8) \cdot \mathrm{a}(18) \& \mathrm{~g}(9) \cdot \mathrm{a}(17) \& \mathrm{~g}(10) \cdot \mathrm{a}(16) \& \mathrm{~g}(11) \cdot \mathrm{a}(1$ 5) $\& \mathrm{~g}(12) \cdot \mathrm{a}(14) \& \mathrm{~g}(13) \cdot \mathrm{a}(13) \& \mathrm{~g}(14) \cdot \mathrm{a}(12) \& \mathrm{~g}(15) \cdot \mathrm{a}(11) \& \mathrm{~g}(16) \cdot \mathrm{a}(10) \& \mathrm{~g}(17) \cdot \mathrm{a}(9) \& \mathrm{~g}(18) \cdot \mathrm{a}(8) \& \mathrm{~g}(19) \cdot \mathrm{a}(7) \& \mathrm{~g}(20)$. $\mathrm{a}(6) \& \mathrm{~g}(21) \cdot \mathrm{a}(5) \& \mathrm{~g}(22) \cdot \mathrm{a}(4)+\mathrm{g}(1) \cdot \mathrm{a}(26) \& \mathrm{~g}(2) \cdot \mathrm{a}(25) \& \mathrm{~g}(3) \cdot \mathrm{a}(24) \& \mathrm{~g}(4) \cdot \mathrm{a}(23) \& \mathrm{~g}(5) \cdot \mathrm{a}(22) \& \mathrm{~g}(6) \cdot \mathrm{a}(21) \& \mathrm{~g}(7) \cdot \mathrm{a}(20)$ $\& \mathrm{~g}(8) \cdot \mathrm{a}(19) \& \mathrm{~g}(9) \cdot \mathrm{a}(18) \& \mathrm{~g}(10) \cdot \mathrm{a}(17) \& \mathrm{~g}(11) \cdot \mathrm{a}(16) \& \mathrm{~g}(12) \cdot \mathrm{a}(15) \& \mathrm{~g}(13) \cdot \mathrm{a}(14) \& \mathrm{~g}(14) \cdot \mathrm{a}(13) \& \mathrm{~g}(15) \cdot \mathrm{a}(12) \& \mathrm{~g}(16) \cdot \mathrm{a}$ (11) $\& \mathrm{~g}(17) \cdot \mathrm{a}(10) \& \mathrm{~g}(18) \cdot \mathrm{a}(9) \& \mathrm{~g}(19) \cdot \mathrm{a}(8) \& \mathrm{~g}(20) \cdot \mathrm{a}(7) \& \mathrm{~g}(21) \cdot \mathrm{a}(6) \& \mathrm{~g}(22) \cdot \mathrm{a}(5)+\mathrm{g}(1) \cdot \mathrm{a}(27) \& \mathrm{~g}(2) \cdot \mathrm{a}(26) \& \mathrm{~g}(3) \cdot \mathrm{a}(25)$ $\& \mathrm{~g}(4) \cdot \mathrm{a}(24) \& \mathrm{~g}(5) \cdot \mathrm{a}(23) \& \mathrm{~g}(6) \cdot \mathrm{a}(22) \& \mathrm{~g}(7) \cdot \mathrm{a}(21) \& \mathrm{~g}(8) \cdot \mathrm{a}(20) \& \mathrm{~g}(9) \cdot \mathrm{a}(19) \& \mathrm{~g}(10) \cdot \mathrm{a}(18) \& \mathrm{~g}(11) \cdot \mathrm{a}(17) \& \mathrm{~g}(12) \cdot \mathrm{a}(16)$ $\& \mathrm{~g}(13) \cdot \mathrm{a}(15) \& \mathrm{~g}(14) \cdot \mathrm{a}(14) \& \mathrm{~g}(15) \cdot \mathrm{a}(13) \& \mathrm{~g}(16) \cdot \mathrm{a}(12) \& \mathrm{~g}(17) \cdot \mathrm{a}(11) \& \mathrm{~g}(18) \cdot \mathrm{a}(10) \& \mathrm{~g}(19) \cdot \mathrm{a}(9) \& \mathrm{~g}(20) \cdot \mathrm{a}(8) \& \mathrm{~g}(21) \cdot \mathrm{a}$ (7) $\& g(22) \cdot a(6)+g(1) \cdot a(28) \& g(2) \cdot a(27) \& g(3) \cdot a(26) \& g(4) \cdot a(25) \& g(5) \cdot a(24) \& g(6) \cdot a(23) \& g(7) \cdot a(22) \& g(8) \cdot a(21) \&$ $\mathrm{g}(9) \cdot \mathrm{a}(20) \& \mathrm{~g}(10) \cdot \mathrm{a}(19) \& \mathrm{~g}(11) \cdot \mathrm{a}(18) \& \mathrm{~g}(12) \cdot \mathrm{a}(17) \& \mathrm{~g}(13) \cdot \mathrm{a}(16) \& \mathrm{~g}(14) \cdot \mathrm{a}(15) \& \mathrm{~g}(15) \cdot \mathrm{a}(14) \& \mathrm{~g}(16) \cdot \mathrm{a}(13) \& \mathrm{~g}(17) \cdot \mathrm{a}($ 12) $\& \mathrm{~g}(18) \cdot \mathrm{a}(11) \& \mathrm{~g}(19) \cdot \mathrm{a}(10) \& \mathrm{~g}(20) \cdot \mathrm{a}(9) \& \mathrm{~g}(21) \cdot \mathrm{a}(8) \& \mathrm{~g}(22) \cdot \mathrm{a}(7)\}$ 
758 Part 3.EXAMPLE 1: Matrix description of one of the simplest heterogeneity model

759 The 5-state model with heterogeneity in survival only (Fig. 2 in the main text) is

760 described in Table S1. As all models considered in this study, it includes the possibility to

761 emigrate temporarily, and also to record information on the breeding status; otherwise it

762 reduces to Pledger et al.'s (2003) two-class finite mixture model $\left\{\Phi\left(h_{2}\right), p(t)\right\}$ (see also

763 Pradel 2009). If the two survival-classes and the two "status confirmation events" are merged

764 together this model becomes the temporary emigration model of Fujiwara and Caswell

765 (2002).

766 
Péron et al.

\section{TABLE S1}

768 Matrix description of a multievent model accounting for survival heterogeneity using two classes, while allowing for temporary emigration and detailed observation structure. (a)

770 Survival probabilities (S-matrix): $\varphi_{1}$ and $\varphi_{2}$ are the two survival probabilities (high and low)

771 (b) Transition probabilities ( $\Psi$-matrix): $\psi$ and $\psi$ ' are the emigration and return transition

772 probabilities respectively. The product $\Phi=\mathrm{S} \times \Psi$ constitutes the survival/transition matrix that

773 is common to multistate and multievent models. (c) Event probabilities (B-matrix): $\mathrm{p}$ and $\mathrm{r}$

774 are respectively detection and breeding status assignment probabilities. There is no

775 heterogeneity in detection in this example model.

776 States $\mathrm{S} 1$ and $\mathrm{S} 2$ code for the two survival classes in the study site, while AE1 and AE2 code

777 for them in the "Alive Elsewhere" site. There were three possible observations following

778 initial release (0: not seen, 1: seen and breeding status confirmed; 2 : seen but breeding status not confirmed), which correspond to the three columns of the B-matrix.

780

(a) $\mathrm{S}$

\begin{tabular}{cccccc}
\hline & S1 & S2 & AE1 & AE2 & Dead \\
\hline S1 & $\varphi_{1}$ & 0 & 0 & 0 & $1-\varphi_{1}$ \\
S2 & 0 & $\varphi_{2}$ & 0 & 0 & $1-\varphi_{2}$ \\
AE1 & 0 & 0 & $\varphi_{1}$ & 0 & $1-\varphi_{1}$ \\
AE2 & 0 & 0 & 0 & $\varphi_{2}$ & $1-\varphi_{2}$ \\
dead & 0 & 0 & 0 & 0 & 1 \\
\hline \multicolumn{7}{r}{} & S1 & S2 & AE1 & AE2 & Dead \\
\hline S1 & $1-\psi$ & 0 & $\psi$ & 0 & 0 \\
S2 & 0 & $1-\psi$ & 0 & $\psi$ & 0 \\
AE1 & $\psi^{\prime}$ & 0 & $1-\psi^{\prime}$ & 0 & 0 \\
AE2 & 0 & $\psi^{\prime}$ & 0 & $1-\psi^{\prime}$ & 0 \\
dead & 0 & 0 & 0 & 0 & 1 \\
\hline
\end{tabular}

(c)

$\mathrm{B}=\mathrm{P} \times \mathrm{R}$

\begin{tabular}{cccc} 
& $\mathbf{0}$ & $\mathbf{1}$ & $\mathbf{2}$ \\
\hline $\mathbf{S 1}$ & $1-\mathrm{p}$ & $\mathrm{p} \times \mathrm{r}$ & $\mathrm{p} \times(1-\mathrm{r})$ \\
S2 & $1-\mathrm{p}$ & $\mathrm{p} \times \mathrm{r}$ & $\mathrm{p} \times(1-\mathrm{r})$ \\
$\mathbf{A E 1}$ & 1 & 0 & 0 \\
AE2 & 1 & 0 & 0 \\
dead & 1 & 0 & 0 \\
\hline
\end{tabular}




\section{Part 4. EXAMPLE 2: Matrix description of the most complex model}

considered in this study, it includes the possibility to emigrate temporarily, and also to record information on the breeding status; otherwise it reduces to Pledger et al.'s (2003) two-class finite mixture model $\left\{\Phi\left(h_{2}\right), p\left(h_{2}+t\right)\right\}$ (see also Pradel, 2008). If the eight heterogeneity classes and the two "status confirmation events" are merged together this model becomes the temporary emigration model of Fujiwara and Caswell (2002). breeding in LR can be in one of the 8 states denoted $\mathrm{S}_{\mathrm{i}} \mathrm{D}_{\mathrm{j}} \mathrm{E}_{\mathrm{k}}$, where $i, j, k$ can be "low" or "high". An individual in state $S_{\text {low }} D_{\text {high }} E_{\text {high }}$ for example has low survival, high capture and high emigration probabilities. Alternatively, the bird can be "Alive elsewhere" in states $\mathrm{AES}_{\text {low }}$ and $\mathrm{AES}_{\text {high }}$, or it can be dead, a state that is explicitly included in the model. The recorded events are '0' for “not seen", ' 1 ' for "seen as confirmed breeder", and '2' for "seen as unconfirmed breeder". In addition to the matrix description we provide for this model more detail of the practical implementation, in the form of the GEPAT/GEMACO instructions. These are the interfaces of E-SURGE that are used to constrain multievent models (Choquet et al. 2009a). 
Péron et al.

p. 42

801

802

803

804 805 States denominations are described above.

\begin{tabular}{|c|c|c|c|c|c|c|c|c|c|c|c|}
\hline \multirow[b]{2}{*}{ Tolfrom } & \multicolumn{11}{|c|}{ State at time $t$} \\
\hline & 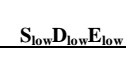 & 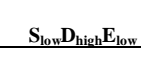 & $\mathbf{S}_{\text {lov }} \mathbf{D}_{\text {lov }} \mathbf{E}_{\text {hish }}$ & $\mathbf{S}_{\text {lon }} \mathbf{D}_{\text {hiek h }} \mathbf{E}_{\text {hieh }}$ & $S_{\text {wieb }} \mathbf{D}_{\text {ove }} \mathbf{E}_{\text {ow }}$ & $\mathbf{S}_{\text {hieh }} \mathbf{D}_{\text {hieh }} \mathbf{E}_{\text {low }}$ & $\mathbf{S}_{\text {nieh }} \mathbf{D}_{\text {low }} \mathbf{E}_{\text {hiel }}$ & $\mathbf{S}_{\text {hieh }} \mathbf{W}_{\text {hies }} \mathbf{E}_{\text {hiet }}$ & ${ }_{n} \quad \mathrm{AES}_{\text {low }}$ & $\mathbf{A E S}_{\text {with }}$ & dead \\
\hline $\mathbf{S}_{\mathrm{lov}} \mathbf{D}_{\mathrm{lov}} \mathrm{E}_{\mathrm{Elow}}$ & $\varphi_{1}$ & 0 & 0 & 0 & 0 & 0 & 0 & 0 & 0 & 0 & $1-\varphi_{1}$ \\
\hline $\mathbf{S}_{\text {low }} \boldsymbol{D}_{\text {ingh }} \mathbf{E}_{\text {low }}$ & 0 & $\varphi_{1}$ & 0 & 0 & 0 & 0 & 0 & 0 & 0 & 0 & $1-\varphi_{1}$ \\
\hline $\mathbf{S}_{\text {low }} \mathbf{D}_{\text {low }} \mathbf{E}_{\text {nigh }}$ & 0 & 0 & $\varphi_{1}$ & 0 & 0 & 0 & 0 & 0 & 0 & 0 & $1-\varphi_{1}$ \\
\hline $\mathbf{S}_{\text {lon }} \boldsymbol{D}_{\text {igizh }} \mathbf{E}_{\text {high }}$ & 0 & 0 & 0 & $\varphi_{1}$ & 0 & 0 & 0 & 0 & 0 & 0 & $1-\varphi_{1}$ \\
\hline$s_{\text {wien }} \mathbf{D}_{\text {oow }} \mathbf{E}_{\text {ow }}$ & 0 & 0 & 0 & 0 & $\varphi_{2}$ & 0 & 0 & 0 & 0 & 0 & $1-\varphi_{2}$ \\
\hline $\mathbf{S}_{\text {wiph }} \mathbf{D}_{\text {high }} \mathbf{E}_{\text {low }}$ & 0 & 0 & 0 & 0 & 0 & $\varphi_{2}$ & 0 & 0 & 0 & 0 & $1-\varphi_{2}$ \\
\hline $\mathbf{S}_{\text {high }} \mathbf{D}_{\text {low }} \mathbf{E}_{\text {high }}$ & 0 & 0 & 0 & 0 & 0 & 0 & $\varphi_{2}$ & 0 & 0 & 0 & $1-\varphi_{2}$ \\
\hline $\mathbf{S}_{\text {high }} \mathbf{B}_{\text {niqh }} \mathbf{E}_{\text {iegh }}$ & 0 & 0 & 0 & 0 & 0 & 0 & 0 & $\varphi_{2}$ & 0 & 0 & $1-\varphi_{2}$ \\
\hline $\mathbf{A E S}_{\text {low }}$ & 0 & 0 & 0 & 0 & 0 & 0 & 0 & 0 & $\varphi_{1}$ & 0 & $1-\varphi_{1}$ \\
\hline $\mathrm{AES}_{\text {high }}$ & 0 & 0 & 0 & 0 & 0 & 0 & 0 & 0 & 0 & $\varphi_{2}$ & $1-\varphi_{2}$ \\
\hline dead & 0 & 0 & 0 & 0 & 0 & 0 & 0 & 0 & 0 & 0 & 1 \\
\hline
\end{tabular}

806

807 The modelling of survival as in Table S2 is done through GEPAT and GEMACO as follow:

808 GEPAT instruction:

809

GEMACO instruction (for the TFC-effect): 
Péron et al.

813 A .txt file is to be entered as an external covariable and codes for the linear effect of age

814 varying between 14 and 24 (11 age classes):

$815 \quad 1$

$816 \quad 11$

$\begin{array}{llllllll}817 & 0.090909091 & 0.181818182 & 0.272727273 & 0.363636364 & 0.454545455 & 0.545454545\end{array}$

$\begin{array}{lllllll}818 & 0.636363636 & 0.727272727 & 0.818181818 & 0.909090909 & 1\end{array}$

819

820

TABLE S3

821

Dispersal probabilities ( $\Psi$-matrix) of multievent model accounting for survival,

822 detection and emigration heterogeneity using two classes, while allowing for temporary

823 emigration and detailed observation structure. The product $\Phi=\mathrm{S} \times \Psi$ constitutes the

824 survival/transition matrix that is common to multistate and multievent models. $\psi_{1}$ and $\psi_{2}$ are

825 the two probabilities of transition from the study site to states "Alive Elsewhere",

826 corresponding to high and low emigration rates. After a temporary emigration, gulls could

827 completely change the location of their nest, thus change of detectability class. Similarly, after

828 an emigration event, gulls could be more site-faithful (if emigration aims at sparing energy for

829 subsequent breeding) or less site faithful (if the first emigration event is the symptom of a

830 decrease in health status). Therefore our model did not constraint the way individual behaved

831 after a temporary emigration: four different probabilities to return to the study site were

832 implemented. The probabilities of coming back to the study colony are four: $\psi_{3}, \psi_{4}, \psi_{5}, \psi_{6}$

833 respectively the transitions, from the corresponding "Alive Elsewhere" states, to states

$834 S_{\text {low }} D_{\text {low }} E_{\text {low }}$ and $S_{\text {high }} D_{\text {low }} E_{\text {low }}, S_{\text {low }} D_{\text {high }} E_{\text {low }}$ and $S_{\text {high }} D_{\text {high }} E_{\text {low }}, S_{\text {low }} D_{\text {low }} E_{\text {high }}$ and $S_{\text {high }} D_{\text {low }} E_{\text {high }}$,

$835 S_{\text {low }} D_{\text {high }} E_{\text {high }}$ and $S_{\text {high }} D_{\text {high }} E_{\text {high. }} . \Sigma \psi$ stands for $\psi_{3}+\psi_{4}+\psi_{5}+\psi_{6}$. States denominations are

836 described above.

837

\begin{tabular}{|c|c|c|c|c|c|c|c|c|c|c|c|}
\hline \multirow[b]{2}{*}{ Tolfrom } & \multicolumn{11}{|c|}{ State before dispersal } \\
\hline & $\mathbf{S}_{\text {low }} \mathbf{D}_{\text {low }} \mathbf{E}_{\text {low }}$ & $\mathbf{S}_{\text {low }} \mathbf{D}_{\text {high }} \mathbf{E}_{\text {low }}$ & $\mathbf{S}_{\operatorname{low}} \mathbf{D}_{\text {low }} \mathbf{E}_{\text {high }}$ & $\mathbf{S}_{\text {low }} \mathbf{D}_{\text {hiph }} \mathbf{E}_{\text {high }}$ & $\mathbf{S}_{\text {hiph }} \mathbf{D}_{0 \mathrm{ow}} \mathbf{E}_{\text {low }}$ & $\mathbf{S}_{\text {high }} \mathbf{D}_{\text {high }} \mathbf{E}_{\text {low }}$ & $\mathbf{S}_{\text {high }} \mathbf{D}_{\text {low }} \mathbf{E}_{\text {high }}$ & $\mathbf{S}_{\text {hiqh }} \mathbf{D}_{\text {hiqh }} \mathbf{E}_{\text {high }}$ & $\mathbf{A E S}_{\text {low }}$ & $\mathbf{A E S}_{\text {high }}$ & dead \\
\hline $\mathbf{S}_{\mathrm{low}} \mathbf{D}_{\mathrm{low}} \mathbf{E}_{\mathrm{low}}$ & $1-\psi_{1}$ & 0 & 0 & 0 & 0 & 0 & 0 & 0 & $\psi_{1}$ & 0 & 0 \\
\hline $\mathbf{S}_{\text {low }} \mathbf{D}_{\text {high }} \mathbf{E}_{\text {low }}$ & 0 & $1-\psi_{1}$ & 0 & 0 & 0 & 0 & 0 & 0 & $\psi_{1}$ & 0 & 0 \\
\hline
\end{tabular}


Péron et al.

\begin{tabular}{|c|c|c|c|c|c|c|c|c|c|c|}
\hline $\mathrm{S}_{\mathrm{low}} \mathrm{D}_{\mathrm{low}} \mathrm{E}_{\text {high }}$ & 0 & 0 & $1-\psi_{2}$ & 0 & 0 & 0 & 0 & 0 & $\psi_{2}$ & 0 \\
\hline $\mathbf{S}_{\text {lou }} \mathbf{D}_{\text {high }} \mathbf{E}_{\text {high }}$ & 0 & 0 & 0 & $1-\psi_{2}$ & 0 & 0 & 0 & 0 & $\psi_{2}$ & 0 \\
\hline $\mathbf{S}_{\text {high }} \mathbf{D}_{\text {low }} \mathbf{E}_{\text {low }}$ & 0 & 0 & 0 & 0 & $1-\psi_{1}$ & 0 & 0 & 0 & 0 & $\psi_{1}$ \\
\hline $\mathbf{S}_{\text {nigh }} \mathbf{D}_{\text {nigh }} \mathbf{E}_{\text {low }}$ & 0 & 0 & 0 & 0 & 0 & $1-\psi_{1}$ & 0 & 0 & 0 & $\psi_{1}$ \\
\hline$S_{\text {hiph }} \mathbf{D}_{\text {Iov }} \mathbf{E}_{\text {high }}$ & 0 & 0 & 0 & 0 & 0 & 0 & $1-\psi_{2}$ & 0 & 0 & $\psi_{2}$ \\
\hline $\mathbf{S}_{\text {high }}$ Dhigh $_{\text {high }}$ & 0 & 0 & 0 & 0 & 0 & 0 & 0 & $1-\psi_{2}$ & 0 & $\psi_{2}$ \\
\hline $\mathbf{A E S}_{\text {low }}$ & $\psi_{3}$ & $\psi_{4}$ & $\psi_{5}$ & $\psi_{6}$ & 0 & 0 & 0 & 0 & $1-\Sigma \psi$ & 0 \\
\hline $\mathbf{A E S}_{\text {high }}$ & 0 & 0 & 0 & 0 & $\psi_{3}$ & $\psi_{4}$ & $\psi_{5}$ & $\psi_{6}$ & 0 & $1-\Sigma \psi$ \\
\hline dead & 0 & 0 & 0 & 0 & 0 & 0 & 0 & 0 & 0 & 0 \\
\hline
\end{tabular}

839 The modelling of dispersal as in Table S3 is done through GEPAT and GEMACO as follow:

840 GEPAT instruction:

841

$\begin{array}{lllllllllll}* & 0 & 0 & 0 & 0 & 0 & 0 & 0 & \psi & 0 & 0 \\ 0 & * & 0 & 0 & 0 & 0 & 0 & 0 & \psi & 0 & 0 \\ 0 & 0 & * & 0 & 0 & 0 & 0 & 0 & \psi & 0 & 0 \\ 0 & 0 & 0 & * & 0 & 0 & 0 & 0 & \psi & 0 & 0 \\ 0 & 0 & 0 & 0 & * & 0 & 0 & 0 & 0 & \psi & 0 \\ 0 & 0 & 0 & 0 & 0 & * & 0 & 0 & 0 & \psi & 0 \\ 0 & 0 & 0 & 0 & 0 & 0 & * & 0 & 0 & \psi & 0 \\ 0 & 0 & 0 & 0 & 0 & 0 & 0 & * & 0 & \psi & 0 \\ \psi & \psi & \psi & \psi & 0 & 0 & 0 & 0 & * & 0 & 0 \\ 0 & 0 & 0 & 0 & \psi & \psi & \psi & \psi & 0 & * & 0 \\ 0 & 0 & 0 & 0 & 0 & 0 & 0 & 0 & 0 & 0 & *\end{array}$

842

GEMACO instruction:

843

f(1 35 7,2 468$)+f(9$ 10).to

844

845

TABLE S4

846

Detection probabilities (P-matrix) and breeding status confirmation probabilities (R-

847 matrix) of multievent model accounting for survival, detection and emigration heterogeneity

848 using two classes, while allowing for temporary emigration and detailed observation

849 structure. Product $\mathrm{P} \times \mathrm{R}$ constitutes the matrix of event probabilities ( $\mathrm{B}$-matrix), which

850 represents the probabilities of recording the events conditional on the occupied state. The

851 "observation status" ["not seen", "seen 1" (seen with a high detection probability), "seen 2" 
Péron et al.

852 (seen with a low detection probability)] corresponds to transitory states. Then there were three

853 possible events ( 0 : not seen, 1 : seen and breeding status confirmed; 2 : seen but breeding status

854 not confirmed), which correspond to the three columns of R. $\mathrm{p}_{\text {low }}$ and $\mathrm{p}_{\text {high }}$ are the two

855 detection probabilities; $r_{\text {low }}$ and $r_{\text {high }}$ are the corresponding probabilities of confirming

856 breeding status. States denominations are described above.

(a) $\mathbf{P}$

\begin{tabular}{ccc}
\hline \multicolumn{3}{l}{ Observation status } \\
\hline $\begin{array}{c}\text { not } \\
\text { seen }\end{array}$ Seen1 & Seen2 \\
\hline
\end{tabular}

857

\begin{tabular}{|c|c|c|c|c|}
\hline & & seen & Seen1 & Seen2 \\
\hline \multirow{11}{*}{ 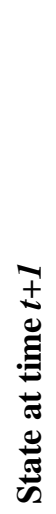 } & $\mathbf{S}_{\mathrm{low}} \mathbf{D}_{\mathrm{low}} \mathbf{E}_{\mathrm{low}}$ & 1-plow & plow & 0 \\
\hline & $\mathbf{S}_{\mathrm{low}} \mathbf{D}_{\text {high }} \mathbf{E}_{\text {low }}$ & $1-p_{\text {high }}$ & 0 & phigh \\
\hline & $\mathbf{S}_{\text {low }} \mathbf{D}_{\text {low }} \mathbf{E}_{\text {high }}$ & 1-plow & plow & 0 \\
\hline & $\mathbf{S}_{\text {low }} \mathbf{D}_{\text {high }} \mathbf{E}_{\text {high }}$ & 1-phigh & 0 & phigh \\
\hline & $\mathbf{S}_{\text {high }} \mathbf{D}_{\text {low }} \mathbf{E}_{\text {low }}$ & 1-plow & plow & 0 \\
\hline & $\mathbf{S}_{\text {high }} \mathbf{D}_{\text {high }} \mathbf{E}_{\text {low }}$ & 1-phigh & 0 & phigh \\
\hline & $\mathbf{S}_{\text {high }} \mathbf{D}_{\text {low }} \mathbf{E}_{\text {high }}$ & 1-plow & plow & 0 \\
\hline & $\mathbf{S}_{\text {high }} \mathbf{D}_{\text {high }} \mathbf{E}_{\text {high }}$ & $1-p_{\text {high }}$ & 0 & $\mathrm{p}_{\text {high }}$ \\
\hline & $\mathbf{A E S}_{\text {low }}$ & 1 & 0 & 0 \\
\hline & $\mathbf{A E S}_{\text {high }}$ & 1 & 0 & 0 \\
\hline & dead & 1 & 0 & 0 \\
\hline
\end{tabular}

(b) $\mathbf{R}$

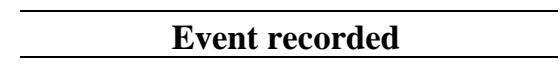

\begin{tabular}{|c|c|c|c|c|c|}
\hline & & & $\mathbf{0}$ & 1 & 2 \\
\hline \multirow{3}{*}{ 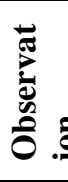 } & \multirow{3}{*}{ ఏ气 } & $\begin{array}{c}\text { not } \\
\text { seen }\end{array}$ & 1 & 0 & 0 \\
\hline & & Seen1 & 0 & $\mathrm{r}_{\text {low }}$ & $1-r_{\text {low }}$ \\
\hline & & Seen2 & 0 & rhigh & 1-rhigh \\
\hline
\end{tabular}

858 The modelling of event recording as in Table S4 is done through GEPAT and GEMACO as

859 follow:

860 GEPAT instruction for detection:

861 GEPAT instruction for breeding status confirmation:

$\begin{array}{lll}* & \beta & - \\ * & - & \beta \\ * & \beta & - \\ * & - & \beta \\ * & \beta & - \\ * & - & \beta \\ * & \beta & - \\ * & - & \beta \\ * & - & - \\ * & - & - \\ * & - & -\end{array}$

$-\beta *$

$-\beta *$

863 GEMACO instruction for detection (modelling time-dependence): 
Péron et al.

$$
\mathbf{a}(1)+\mathbf{a}(2: 29) \cdot[\text { to+t }]
$$

865 GEMACO instruction for breeding status confirmation:

\section{from}

867

868

869

870

871

872

873

874

875

876

877

878

879

880

881

882

883

884

885

886

887

888

\section{References quoted in this Appendix}

Aebischer, N.J. and Coulson, J.C. 1990. Survival of the Kittiwake in relation to sex, year, breeding experience and position in the colony. - J. Anim. Ecol 59: 1063-71.

Choquet, R. 2008. Automatic generation of multistate capture-recapture models. - Can. J. Stat. 36: 43-57.

Choquet, R. et al. 2009a. Program E-SURGE: a software application for fitting Multievent models. - In: Thomson, D. L. Cooch, E. G. and Conroy, M. J. (eds.), Modelling

Frederiksen, M. et al. 2004. Estimating true age-dependance in survival when only adults can be observed: an example with Black-legged Kittiwakes. - Anim. Biodivers. Conserv. 27: $541-48$

Fujiwara, M. and Caswell, H. 2002. A general approach to temporary emigration in markrecapture analysis. - Ecology 83: 3266-75.

Goodman, L.A. 1961. Statistical methods for the mover-stayer model. - J. Am. Stat. Assoc. 56: $841-68$.

Jones, O.R. et al. 2008. Senescence rates are determined by ranking on the fast-slow lifehistory continuum. - Ecol. Lett. 11: 664-73.

Loison, A. et al. 1999. Age-specific survival in five populations of ungulates: evidence of senescence. - Ecology 80: 2539-54.

Nichols, J.D. et al. 1997. Test for senescent decline in annual survival probabilities of common pochard, Aythia ferina. - Ecology 78: 1009-18. 
Péron et al.

889 Pledger, S. et al. 2003. Open capture-recapture models with heterogeneity: I. Cormack-Jolly$890 \quad$ Seber model. - Biometrics 59: 786-94.

891 Pradel, R. 2009. The stakes of capture-recapture models with state uncertainty. - In:

892 Thomson, D. L. Cooch, E. G. and Conroy, M. J. eds. Modelling Demographic Processes in 893 Marked Populations, pp. 781-795.

894 Prévot-Julliard, A.C. et al. 1998a. Re-evaluation of adult survival of Black-headed Gulls

895 Larus ridibundus in presence of recapture heterogeneity. - Auk 115: 85-95.

896 Prévot-Julliard, A.C. et al. 1998b. Evidence for birth-site tenacity in breeding Common

897 Black-headed Gulls, Larus ridibundus. - Can. J. Zool. 76: 2295-98.

898 Pugesek, et al. 1995. Mark-resighting analysis of a California gull population. - J. Appl. Stat. $89922: 625-39$.

900 R Development Core Team 2008. R: A language and environment for statistical computing. 901 R Foundation for Statistical Computing, Vienna, Austria. 


\section{Appendix S2: Simulation study}

904

905

906

907

908

909

910

911

912

913

914

915

916

917

918 individuals were released in each of the eight classes of heterogeneity, forming an overall

Because the performances of multievent CMR models have never been formally tested in the presence of several sources of heterogeneity, we carried out three simulation studies.

- The first simulated situation was the absence of senescence and the presence of three kinds of heterogeneity (survival, detection, emigration). It aimed at evaluating the performance of our information-theoretic approach concerning type II errors (i.e. the probability to falsely detect the presence of senescence).

- The second simulated case was the presence of senescence and of the three kinds of heterogeneity, but without the detailed information on detectability, i.e. there was only two events possible ("seen" / "not seen"). It aimed at illustrating potential issues related to the mixing of detection and emigration heterogeneity.

- The third simulated case was the presence of senescence, three sources of heterogeneity, and detailed data structure (i.e. the frequency of the observed events depended on the detection probability; see "data simulation" below). There were three events possible (“seen 1", “seen 2", "not seen”).

\section{Data simulation}

The simulation studies were based on 30 simulated datasets (except for case \#2 where we used 60 datasets). The time needed to perform each of these exercises exceeded 10 days each with an Intel Pentium 4HT, 2.6GHz (3.25 x 800) processor with $512 \mathrm{Mb}$ of system memory.

Datasets were simulated as follows. At each of 20 capture sessions, 50 newly marked sample size of 8000 individuals. Between each session, individuals were allowed to move to 
or from a site where detection was impossible. The eight classes had different values of demographic parameters: probability of survival (at age 1 before senescence) was 0.8 or 0.5 ; of detection 0.5 or 0.1 ; and of changing site 0.4 or 0.1 .

When present in the simulated case, the detailed observation structure was simulated as follows. In the high-detectability class, at each session $80 \%$ of the detected individuals produced the event "seen 1 " and $20 \%$ the event "seen 2 ". In the low-detectability class the frequency of "seen1" was $20 \%$ and the frequency of "seen2" was $80 \%$.

When present in the simulated case, senescence was simulated as a linear decrease in survival with age starting at age 1 and with a slope of -0.033 and -0.021 year $^{-1}$ in the high and low survival classes respectively (Fig. S1), i.e. survival probability was zero at age 25 . We deliberately chose to simulate a linear effect (and not a logit-linear effect), so that, as is supposedly the case in real datasets, the logit-linear relationship between age and survival that was used in the CMR model was only approximating the underlying process.

\section{Data analysis}

Ten models were fitted on each simulated datasets: $\left\{\mathrm{S}_{0+\bar{a}} ; \mathrm{D}_{0} ; \mathrm{E}_{0}\right\},\left\{\mathrm{S}_{0+\mathrm{a}} ; \mathrm{D}_{0} ; \mathrm{E}_{0}\right\}$, $\left\{\mathrm{S}_{0+\overline{\mathrm{a}}} ; \mathrm{D}_{\mathrm{H}} ; \mathrm{E}_{\mathrm{H}}\right\},\left\{\mathrm{S}_{0+\mathrm{a}} ; \mathrm{D}_{\mathrm{H}} ; \mathrm{E}_{\mathrm{H}}\right\},\left\{\mathrm{S}_{\mathrm{H}+\overline{\mathrm{a}}} ; \mathrm{D}_{0} ; \mathrm{E}_{\mathrm{H}}\right\},\left\{\mathrm{S}_{\mathrm{H}+\mathrm{a}} ; \mathrm{D}_{0} ; \mathrm{E}_{\mathrm{H}}\right\},\left\{\mathrm{S}_{\mathrm{H}+\overline{\mathrm{a}}} ; \mathrm{D}_{\mathrm{H}} ; \mathrm{E}_{0}\right\},\left\{\mathrm{S}_{\mathrm{H}+\mathrm{a}} ; \mathrm{D}_{\mathrm{H}} ; \mathrm{E}_{0}\right\}$, $\left\{\mathrm{S}_{\mathrm{H}+\bar{a}} ; \mathrm{D}_{\mathrm{H}} ; \mathrm{E}_{\mathrm{H}}\right\}$ and $\left\{\mathrm{S}_{\mathrm{H}+\mathrm{a}} ; \mathrm{D}_{\mathrm{H}} ; \mathrm{E}_{\mathrm{H}}\right\}$. See main text for the meaning of the symbols. For each dataset-model, we computed the AIC, AIC-weights, and parameter estimates, and for each dataset we computed the importance value of the four considered effects (age-effect on survival, heterogeneity in survival, detection and emigration probabilities; see method in main text). To spare computer time we did not estimate the rank of the models and therefore did not formally detect identifiability problems if they occurred (Rouan et al. 2009; Choquet et al. 2009a), nor did we compute standard errors on the estimates. 
Péron et al.

\section{RESULTS}

951

952

953

954

955

956

957

958

959

960

961

962

963

964

965

966

967

968

969

970

971

\section{CASE \#1: ABSENCE OF SENESCENCE, DETAILED DATA}

- Model selection

The three kinds of heterogeneity were unambiguously selected. Their importance values were 1 . Among the 30 datasets, and using the 2-point AIC threshold, model $\left\{\mathrm{S}_{\mathrm{H}+\mathrm{a}} ; \mathrm{D}_{\mathrm{H}} ; \mathrm{E}_{\mathrm{H}}\right\}$ was selected 18 times and model $\left\{\mathrm{S}_{\mathrm{H}+\overline{\mathrm{a}}} ; \mathrm{D}_{\mathrm{H}} ; \mathrm{E}_{\mathrm{H}}\right\}$ (i.e. the model used to simulate the data) 16 times. Thus, despite its absence, the age-effect on survival was selected in more than half the cases.

- Slope of the age-effect where it should have been absent

We computed the average estimated slope of the age-effect (on a logit scale) over the 30 models $\left\{\mathrm{S}_{\mathrm{H}+\mathrm{a}} ; \mathrm{D}_{\mathrm{H}} ; \mathrm{E}_{\mathrm{H}}\right\}$. In the low-survival class, the slope estimate was always very positive (average \pm SD over the 30 datasets: $+0.26 \pm 0.05$ ), i.e. not compatible with senescence. Why the models included this strong increase from a low survival at age 1 to a high survival at old age in the low-survival class is not known, but supposedly stems from the quick decrease with age in sample size of low-survival individuals (see discussion). In the high-survival class, the estimated slope was on average positive and closer to zero (average \pm SD over the 30 datasets: $+0.042 \pm 0.059$ ). Type II errors for senescence (i.e. negative slopes) occurred in 9 out of 30 cases. Over these 9 cases, the slope was still on average close to zero $(-0.027 \pm 0.022$ on a logit scale, compared to the value obtained in the gull application: -0.16). In short, even if the age effect was selected in more than half of the datasets, the estimated slope in the high-survival class was small and most of the time positive and thus did not provide strong evidence for senescence. 
Péron et al.

973

974

975

976

977

978

979

980

981

982

983

984

985

986

987

988

989

990

991

992

993

994

995

996

\section{CASE \#2: PRESENCE OF SENESCENCE, NON-DETAILED DATA}

- Model selection

Among the 60 datasets, and using the 2-point AIC threshold, model $\left\{\mathrm{S}_{\mathrm{H}+\mathrm{a}} ; \mathrm{D}_{0} ; \mathrm{E}_{\mathrm{H}}\right\}$ was selected 50 times, model $\left\{\mathrm{S}_{\mathrm{H}+\mathrm{a}} ; \mathrm{D}_{\mathrm{H}} ; \mathrm{E}_{\mathrm{H}}\right\}$ (i.e. the model used to simulate the data) 20 times only, model $\left\{\mathrm{S}_{\mathrm{H}+\mathrm{a}} ; \mathrm{D}_{\mathrm{H}} ; \mathrm{E}_{0}\right\} 11$ times, and model $\left\{\mathrm{S}_{0+\bar{a}} ; \mathrm{D}_{\mathrm{H}} ; \mathrm{E}_{\mathrm{H}}\right\}$ once. Thus, the age-effect and the survival heterogeneity were generally selected. The two other kinds of heterogeneity proved harder to detect. Importance values of the considered effects were high (Table S5), with the only exception of heterogeneity in detection probability. This issue is discussed under "potential identifiability issues".

When neglecting heterogeneity in survival, in 45 out of 60 cases the age-effect was discarded (by AIC); this confirmed the strong bias due to neglecting survival heterogeneity. When neglecting heterogeneity in detection or emigration the age-effect was always selected except for 3 cases. Therefore, under the simulated scenario, these sources of heterogeneity had a reduced impact on the detection of survival senescence.

- Slope of senescence

In the high-survival class the estimated slope of $-0.11 \pm 0.02$ on a logit scale (average \pm SD over the 60 datasets) translated into a -0.023 year $^{-1}$ (expected value: -0.033 year $^{-1}$ ).

The slope was of slightly lower magnitude in the model without emigration heterogeneity than in the model with it (it was the case in 49 cases out of 60; average slope $0.09 \pm 0.02$ instead of $-0.11 \pm 0.02$ ). Therefore, the impact of emigration heterogeneity on the estimation of senescence received some support.

\section{CASE \#3: PRESENCE OF SENESCENCE, DETAILED DATA (3 EVENTS)}

- Model selection 
Among the 30 datasets, and using the 2-point AIC threshold, model $\left\{\mathrm{S}_{\mathrm{H}+\mathrm{a}} ; \mathrm{D}_{\mathrm{H}} ; \mathrm{E}_{\mathrm{H}}\right\}$ (i.e.

998 the model used to simulate the data) was selected 26 times, model $\left\{\mathrm{S}_{\mathrm{H}+\mathrm{a}} ; \mathrm{D}_{\mathrm{H}} ; \mathrm{E}_{0}\right\} 11$ times,

$999 \operatorname{model}\left\{\mathrm{S}_{0+\mathrm{a}} ; \mathrm{D}_{\mathrm{H}} ; \mathrm{E}_{\mathrm{H}}\right\}$ twice, and model $\left\{\mathrm{S}_{\mathrm{H}+\overline{\mathrm{a}}} ; \mathrm{D}_{\mathrm{H}} ; \mathrm{E}_{\mathrm{H}}\right\}$ three times. The age-effect, the survival

1000 heterogeneity, and the detection heterogeneity (contrary to Case \#2) were unambiguously

1001 selected when relying on importance values (Table S5). Emigration heterogeneity was

1002 slightly less frequently detected. The three preferred models often ended up very close to one

1003 another.

1004

- Slope of senescence

1005

In the high-survival class the estimated slope of $-0.16 \pm 0.02$ (average \pm SD over the

1006 30 datasets) on a logit scale translated into -0.0329 year $^{-1}$ on a linear scale (expected value: $1007 \quad 0.033$ year $\left.^{-1}\right)$.

1008 The slope was not of lower magnitude in the model without emigration heterogeneity 1009 than in the model with it (all cases), and discarding emigration heterogeneity did not prevent

1010 to detect senescence (all cases). Therefore, the impact of emigration heterogeneity on

1011 senescence was not supported in Case \#3.

\section{DISCUSSION}

In Case \#1 the selection of an age-effect when there was none in the data was quite

1015 frequent. However, in most cases the estimated slope of the age-effect in the high-survival 1016 class was small and positive; if we had computed confidence intervals (not performed due to 1017 computer time constraints), we believe these slopes would moreover have appeared non1018 significantly different from zero. The risk of type-II errors for senescence per se therefore 1019 appeared low. Further investigation concerning the surprising find that the low-survival class 1020 was impacted by a strong increase in estimated survival probability is required; for low- 
Péron et al.

1021 survival individuals the interval between the sessions might have been too short to study age

1022 effects on survival.

- Potential identifiability issues

1024

In Case \#2, emigration and detection heterogeneity proved difficult to detect.

1025 Moreover when the importance value of emigration heterogeneity was low, it tended to be

1026 negatively correlated to the importance value of detection heterogeneity (Fig. S2).

1027 Identifiability problems might thus have occurred in some of the simulated cases, between

1028 heterogeneity in detection and in emigration. In other words, the model might have

1029 difficulties separating individuals not seen because emigrated from those not seen because not

1030 detected, hence the large SD on the corresponding importance values in Table S5.

1031 Case \#3 however illustrated how the use of detailed observation data (three events

1032 instead of two, the frequency of each event depending on detectability) made the separation

1033 between detection and emigration processes possible. We thereby suggest that in the study we

1034 present in the main text, our use of the information about breeding status confirmation did

1035 overcome the issue of parameter identifiability raised by Case \#2. Furthermore the tool

1036 implemented in E-SURGE did not detect any problem of parameter redundancy in the gull

1037 study (see main text).

1038

1039

1040

1041 
Péron et al.

p. 54

1042 Table S5: Importance value (IV; see method in main text) of the four considered effects in

1043 three simulation studies. See "data simulation" for the description of the considered cases.

1044 Mean and SD were computed on 30 (Case \#1 and 3) or 60 (Case \#2) simulated datasets.
CASE \#1
CASE \#2
CASE \#3

\begin{tabular}{ccccccc}
\hline Effect considered & Mean & SD & Mean & SD & Mean & SD \\
\hline age-effect on survival & 0.536 & 0.410 & 0.987 & 0.081 & 0.910 & 0.137 \\
heterogeneity in survival & 1.000 & 0.000 & 0.987 & 0.083 & 0.932 & 0.088 \\
heterogeneity in emigration & 1.000 & 0.000 & 0.874 & 0.224 & 0.759 & 0.228 \\
heterogeneity in detection & 1.000 & 0.000 & 0.335 & 0.307 & 1.000 & 0.000 \\
\hline
\end{tabular}

1045

1046 
Péron et al.

p. 55

1047 Figure S1: Simulated variation in survival rate with age in the low- (starting at 0.5) and high-

1048 (starting at 0.8 ) survival classes.

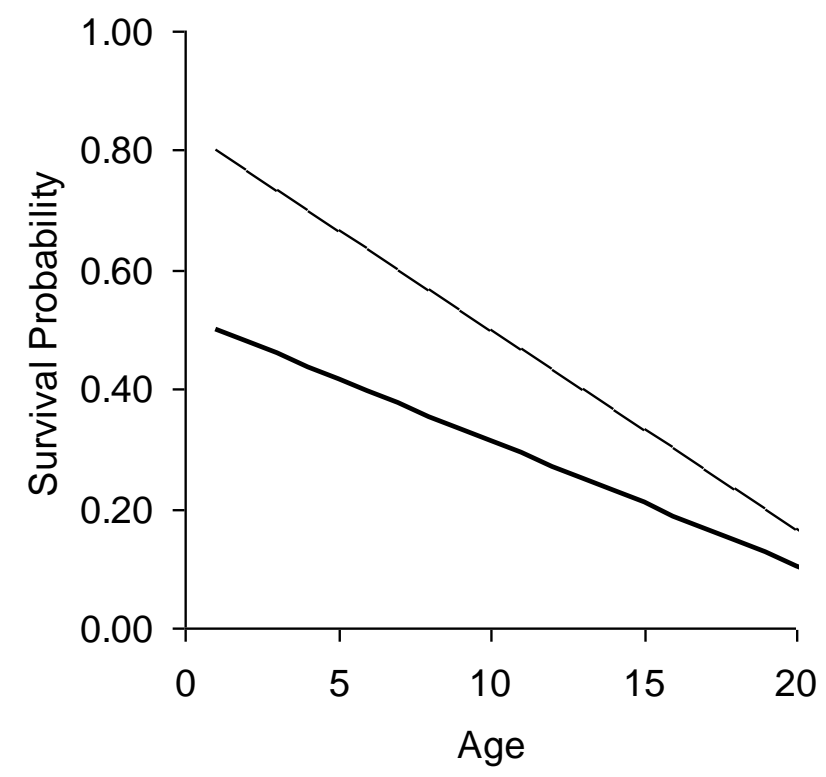

1049

1050 Figure S2: Importance values (IV; see methods in main text) of detection and emigration

1051 heterogeneity computed from the 60 datasets in Case \#2 where the detailed information on detectability was not used.

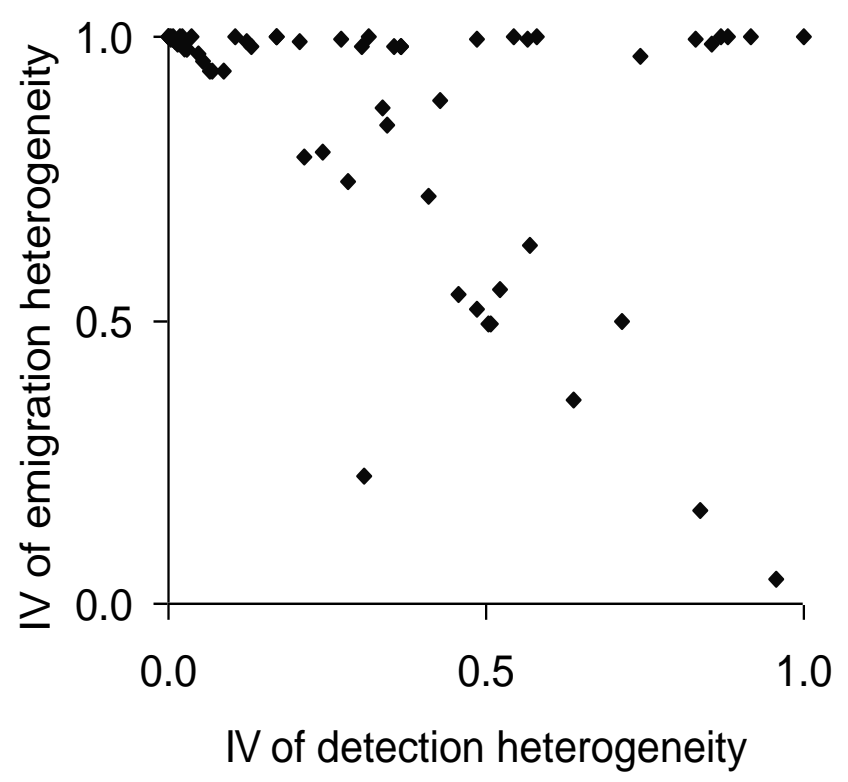

1053 